\title{
Bridging Synaptic and Epigenetic Maintenance Mechanisms of the Engram
}

\author{
Madeleine Kyrke-Smith ${ }^{1,2,3}$ and Joanna M. Williams ${ }^{1 *}$ \\ ' Department of Anatomy, The Brain Health Research Centre, Brain Research New Zealand - Rangahau Roro Aotearoa, \\ University of Otago, Dunedin, New Zealand, ${ }^{2}$ Department of Psychology, The Brain Health Research Centre, Brain Research \\ New Zealand - Rangahau Roro Aotearoa, University of Otago, Dunedin, New Zealand, ${ }^{3}$ Department of Neurobiology and \\ Anatomy, University of Utah, Salt Lake City, UT, United States
}

How memories are maintained, and how memories are lost during aging or disease, are intensely investigated issues. Arguably, the reigning theory is that synaptic modifications allow for the formation of engrams during learning, and sustaining engrams sustains memory. Activity-regulated gene expression profiles have been shown to be critical to these processes, and their control by the epigenome has begun to be investigated in earnest. Here, we propose a novel theory as to how engrams are sustained. We propose that many of the genes that are currently believed to underlie long-term memory are actually part of a "plasticity transcriptome" that underpins structural and functional modifications to neuronal connectivity during the hours to days following learning. Further, we hypothesize that a "maintenance transcriptome" is subsequently induced that includes epigenetic negative regulators of gene expression, particularly histone deacetylases. The maintenance transcriptome negatively regulates the plasticity

Edited by: Peter K. Giese, King's College London, United Kingdom

Reviewed by: Johannes Gräff,

École Polytechnique Fédérale de Lausanne, Switzerland Timothy J. Jarome, Virginia Tech, United States

${ }^{*}$ Correspondence: Joanna M. Williams joanna.williams@otago.ac.nz

Received: 06 August 2018 Accepted: 18 September 2018 Published: 05 October 2018

Citation:

Kyrke-Smith M and Williams JM (2018) Bridging Synaptic and Epigenetic Maintenance Mechanisms of the Engram. Front. Mol. Neurosci. 11:369. doi: 10.3389/fnmol.2018.00369 transcriptome, and thus the plastic capability of a neuron, after learning. In this way, the maintenance transcriptome would act as a metaplasticity mechanism that raises the threshold for change in neurons within an engram, helping to ensure the connectivity is stabilized and memory is maintained.

Keywords: epigenetics, learning, LTP, memory, plasticity

\section{INTRODUCTION}

Networks of strongly connected neurons form the physical trace of declarative, non-declarative and emotional memories as well as habits, sensory associations and motor function (Takeuchi et al., 2013; Josselyn et al., 2015; Eichenbaum, 2016; Poo et al., 2016; Tonegawa et al., 2018). This concept of a physical trace of memory, consisting of networks of cells that have undergone synaptic strengthening and thus preferentially fire together, was postulated by Donald Hebb (Hebb, 1949). Since then, there have been competing arguments throughout the literature about the name given to the physical trace. Here, we refer to the cells activated and involved in a memory, either through experience or through artificial enhancement, as an engram.

The ensemble of neurons involved in an engram is critical to the uniqueness of each memory. Artificially activating an established engram, at the same time as learning something new, can associate the two engrams and thus create a "false memory" without the two events ever being associated in "real life" (Liu et al., 2012; Ramirez et al., 2013, 2015). Further, associating a weak 
learning experience with a strong learning experience causes the respective engrams to overlap, and the retrieval of those associated events then requires the activation of the two overlapping engram (Cai et al., 2016; Nomoto et al., 2016; Abdou et al., 2018). Moreover, disrupting the connectivity of an established engram can erase a memory (Nabavi et al., 2014; Hayashi-Takagi et al., 2015; Roy et al., 2016) and re-connecting or activating the same group neurons can restore it (Nabavi et al., 2014; Roy et al., 2016). Indeed, in vivo visualization of specific synapses modified by a learning event has recently been achieved (Choi et al., 2018). The engram is therefore dependent upon mechanisms which can selectively enhance and refine the synaptic connectivity of neurons. Numerous mechanisms have been identified that can modify synaptic connectivity and are collectively referred to as synaptic plasticity (Citri and Malenka, 2008). However, cell to cell communication is not just dependent upon synaptic transmission. The response of a cell to synaptic activation also depends upon the subsequent conductance of current through the dendritic tree, the depolarization and repolarization at the soma and the conductance of action potentials along the axon (Hausser et al., 2000; Beck and Yaari, 2008; Larkum and Nevian, 2008; Kastellakis et al., 2015). These processes reflect the intrinsic excitability of a neuron (Zhang and Linden, 2003). Thus, engram formation and maintenance is also likely to be critically dependent on modifications to excitability, so called intrinsic plasticity (Zhang and Linden, 2003; Mozzachiodi and Byrne, 2010). Recently, Lisman and colleagues argued strongly for the incorporation of both synaptic and intrinsic plasticity mechanisms into our understanding of memory formation (Lisman et al., 2018). Together, this suggests that there is a central, coordinated response to a learning event, leading to adaptations throughout a given neuron. This central response necessitates a central mechanism, or regulator, to determine successful engram formation and maintenance.

Long-term potentiation (LTP) is an activity dependent and input specific synaptic plasticity mechanism which manifests as enhanced transmission between pre- and post-synaptic regions (Bliss and Gardner Medwin, 1973; Bliss and Lømo, 1973; Bliss and Collingridge, 1993). There is strong support for LTP as the candidate mechanism which incorporates and maintains the specific connectivity of an engram (Bliss and Collingridge, 1993; Abraham and Williams, 2003; Takeuchi et al., 2013; Poo et al., 2016; Choi et al., 2018). The most striking evidence comes from experiments showing that LTP occurs at the same time as learning and that learning occludes further electrically induced LTP (Whitlock et al., 2006; Rioult-Pedotti et al., 2007). Additionally, abolishing the potentiation of the synapses involved in a previously established engram, and then restoring the potentiation using an optogenetic stimulation protocol which has been shown to induce LTP, will erase and then restore the memory, respectively (Nabavi et al., 2014).

Much like learning itself, the induction of LTP also leads to the induction of an array of other synaptic and non-synaptic plasticity mechanisms. For example, less active or inactive synapses surrounding potentiated synapses can be weakened after LTP induction or learning, thereby enhancing the salience of potentiated synapses or removing unwanted inputs
(Lynch et al., 1977; Abraham and Goddard, 1983; Caroni et al., 2014; Nakayama et al., 2015). This can be achieved either by long-term depression (LTD) (Lynch et al., 1977; Abraham and Goddard, 1983) or depotentiation of synapses (Caroni et al., 2014; Nakayama et al., 2015). Further, a cell's intrinsic excitability is also regulated by LTP induction (Andersen et al., 1980; Cai et al., 2016). Thus, LTP, together with the weakening of other synapses and modifications to intrinsic excitability, culminates in changes in the transmission of information within and between neurons after the stimulation protocols used to induce LTP. This evidence supports the notion of a central, coordinated response to plasticity induction. Thus, when considering how LTP or memories are maintained over the long-term it is important to incorporate the cell-wide molecular, anatomical and functional changes throughout the neuron that culminate in the given measured response, be that synaptic strength, cellular activity or memory recall, rather than each individual component alone. Together, this leads to the question; what might be the master regulator of cell-wide plasticity?

It is well accepted that the maintenance of altered synaptic strength, as well as the maintenance of memory, is critically dependent upon changes in gene expression (Goelet et al., 1986; Nguyen et al., 1994). Occurring centrally within the cell, regulated gene expression is a compelling contender as the master regulator of the incorporation of a given neuron into an engram. Seemingly rapid ( $<1 \mathrm{~h}$ post stimulation) changes in the expression of some genes may directly underpin the alterations to synaptic strength by changing the molecular anatomy, and thus function, of the synapses in question (Lyford et al., 1995; Vician et al., 1995; Brakeman et al., 1997; Kato et al., 1997, 1998; Beilharz et al., 1998; Yamagata et al., 1999; Ryan et al., 2011). Simultaneously, substantial changes in the expression of immediate early gene transcription factors (TFs) are concomitant with LTP induction (Cole et al., 1989; Wisden et al., 1990; Jones et al., 2001; Abraham and Williams, 2003, 2008; Ryan et al., 2011). Activation of these TFs have been ascribed to underpinning persistent alterations in synaptic anatomy and strength, by the replenishment of synaptic molecules. However, cellular activity (Dudek and Fields, 2002; Tyssowski et al., 2018), muscarinic or $\beta$-adrenergic receptor activation (Frey et al., 2001) or dopamine activity (Sajikumar and Frey, 2004) all induce similar patterns of gene expression to that which is induced by stimulation protocols that lead to LTP. This suggests that some of the early, transient changes in gene expression that are observed following LTP induction are related to activity, rather than LTP alone. Further, due to the temporal and spatial spread of gene expression after LTP induction and learning, the early gene response may not be specific to the maintenance of an engram over the long-term.

\section{Statement of Hypothesis}

Here, we propose that the genes that are currently associated with LTP and long-term memory (LTM) are part of a "plasticity transcriptome," which reflects a transient "up-state" in neuronal activity at the time of learning or upon the induction of synaptic plasticity. The plasticity transcriptome functions to orchestrate dramatic, widespread changes to the structure and function of a neuron, underpinning altered synaptic plasticity 
and intrinsic excitability. However, in order to allow both consolidation of the engram and ongoing plasticity within a network of neurons a "maintenance transcriptome" develops over hours to days after LTP induction or learning and creates a new metaplastic state. Metaplasticity refers to a shift in the state of a cell that alters the ease or type of plasticity that can be induced by a given stimuli (Abraham and Bear, 1996; Abraham, 2008). We hypothesize that epigenetic mechanisms, in particular histone deacetylation, are central to the maintenance transcriptome and act as the master negative regulators of plasticity by controlling the expression of the plasticity transcriptome, i.e., acting as a metaplastic regulator of gene expression. Accordingly, the ability to modify the structure and function of neurons within a given engram would be attenuated. This epigenetic metaplastic rise in the threshold for change would preferentially maintain the structure of the engram whilst allowing for plasticity within the network, should the new threshold for plasticity be met. This hypothesis is based on the key observations that while gene expression is required for LTM, it is not exclusively related to synaptic enhancement, that canonical gene expression is not sufficient to maintain LTM and that epigenetic mechanisms are activated late after the induction of LTP and regulate plasticity related gene expression.

\section{LONG-TERM POTENTIATION}

Long-term potentiation of specific synapses can be achieved in a myriad of ways, including by real learning experiences (Whitlock et al., 2006), or by in vivo (Bliss and Gardner Medwin, 1973; Bliss and Lømo, 1973; Douglas and Goddard, 1975; Abraham et al., 2002) or in vitro electrical stimulation (Schwartzkroin and Wester, 1975; Alger and Teyler, 1976; Andersen et al., 1980). Infusion of neurotropic factors such as Brain Derived Neurotropic Factor (BDNF) either directly into the brain (Akaneya et al., 1997) or by application to neuronal slice preparations (Kang and Schuman, 1995) can also enhance synaptic transmission, as can a variety of chemical agents modulating glutamatergic and other receptors (Reymann et al., 1986; Thibault et al., 1989; Aniksztejn and Ben-Ari, 1991; Frey et al., 1993; Lu et al., 2001; Fujii et al., 2002; Otmakhov et al., 2004). Therefore, our understanding of the molecular underpinnings of LTP are derived from diverse study protocols, each likely modeling only some aspects of the ensemble of events which come together as a net enhancement in synaptic strength over the long term.

When induced in vivo LTP, like memories, can last for months (Abraham et al., 2002; Abraham, 2003). Electrically-induced LTP is often separated into 2-3 categories. Early LTP (E-LTP or LTP1), lasts only minutes (in vitro) to hours (in vivo) and depends upon post-translational modifications to proteins present at activated synapses (Shirke and Malinow, 1997; Benke et al., 1998). These modifications lead to enhanced currents through receptors, increased numbers of receptors in the postsynaptic density (PSD) and enhanced presynaptic transmitter release (Dolphin et al., 1982; Shirke and Malinow, 1997; Benke et al., 1998). By contrast, late LTP (L-LTP), which arguably is most reliably studied in vivo in the dentate gyrus (DG), lasts for much longer. L-LTP can be divided into an intermediate form, LTP2, which can last for days in vivo, and LTP3 which can last weeks to months in vivo (Abraham et al., 2002; Abraham, 2003; Abraham and Williams, 2003) and is believed to underlie LTM.

Both LTP2 and LTP3 depend upon the synthesis of new plasticity-related proteins (PRPs) (Frey and Morris, 1997) thought to further modify the structure of the synapse (Sacktor et al., 1993; Frey and Morris, 1997; Raymond et al., 2000). Unlike LTP2, LTP3 critically depends upon rapid changes in gene expression. A compelling body of literature shows that a subset of these genes function to expand the range of newly synthesized PRPs available to modify synapses or replenish molecules directly involved in enhancement of synaptic transmission (Abraham and Williams, 2003; Alberini and Kandel, 2015; Sweatt, 2016). These include genes such as Homer (Brakeman et al., 1997; Kato et al., 1997, 1998), Arc (Link et al., 1995; Lyford et al., 1995), Arcadlin (Yamagata et al., 1999), RB-3 (Beilharz et al., 1998), Syt4 (Vician et al., 1995; Ryan et al., 2011) and Nrxn3, Adrb1, Grm6, Chrm4, Chrna4, Grin2D, Gad2 (Ryan et al., 2011). Regulation of the expression of these genes may underpin the structural plasticity at the synapse proposed by Caroni et al. (2014) where synaptic growth, occurring 1-2 h after learning, is followed by strengthening of specific synapses over $12-18 \mathrm{~h}$ and the elimination of spines over the following 1-2 days (Caroni et al., 2014). We hypothesize that these genes comprise the "plasticity transcriptome." Furthermore, transcription factors such as zif/268/Egr1, erg2, egr3 c-jun and jun-b (Cole et al., 1989), and c-fos (Cole et al., 1989; Dragunow et al., 1989) are upregulated simultaneously with the so-called effector genes described above and correspondingly stimulate subsequent waves of gene expression (Nguyen et al., 1994; Dudai, 1996; Abraham, 2003; Abraham and Williams, 2003; Medina et al., 2008; Neves et al., 2008; Josselyn et al., 2015; Tyssowski et al., 2018). The contribution of this mass upregulation of TFs to the maintenance of long-lasting engrams is as yet not adequately resolved.

Interestingly, though the nomenclature of LTP suggests that L-LTP may be an extension of E-LTP, or that LTP1, 2 and 3 may be a continuum, this has not been explicitly proven and indeed, evidence suggests that they may be distinct. The processes necessary for L-LTP, namely protein synthesis and gene expression, are initiated at the same time as LTP is induced, rather than subsequently (Cole et al., 1989; Abraham et al., 1991; Bito et al., 1996; Raymond and Redman, 2006; Benito and Barco, 2015). Further, activation of distinct signaling pathways are needed to induce each type of LTP (Raymond and Redman, 2006). These pathways are not necessarily dependent upon each other but may, or may not, be activated at the same time depending on the induction paradigm (Raymond and Redman, 2006). In particular, stimulation which leads to the induction of LTP1 causes a rise in $\mathrm{Ca}^{2+}$ within dendritic spines via $\mathrm{N}$-methyl-D-aspartate receptor (NMDAR) and ryanodine receptor activity (Raymond and Redman, 2006). LTP2 also appears to also be dependent upon NMDAR activation at synapses, but additionally depends upon metabotropic glutamate receptor (mGluR) activation, leading to inositol 
1,4,5-trisphosphate receptor $\left(\mathrm{IP}_{3} \mathrm{R}\right)$ activated $\mathrm{Ca}^{2+}$ release within dendrites to drive local protein synthesis (Raymond et al., 2000; Raymond and Redman, 2006). Finally, LTP3 has a significant NMDAR independent component which is instead dependent upon $\mathrm{Ca}^{2+}$ rise through L-type voltage-gated calcium channels (L-type VGCC) at the cell body (Raymond and Redman, 2006). Thus, for this paper we take the perspective that LTP3 may well be an independent form of LTP and, as such, must be investigated independently of LTP1 and LTP2. Transcription-dependent LTP is referred to as L-LTP or LTP3 depending upon the classification made within the paper referenced.

\section{Gene Expression Initiated Upon L-LTP Induction and Learning Is Not Exclusively Related to the Enhancement of Synapses}

Upon L-LTP induction, the rapid gene expression response seemingly enables the sustained potentiation of any synapse that is activated to a sufficient degree. Somewhat surprisingly, this degree of activity does not have to be to the extent that would induce L-LTP on its own (Frey and Morris, 1997). The mechanism for this, termed synaptic tag and capture (STC), requires only a "tag" to be set at activated synapses which "captures" newly synthesized PRPs (Frey and Morris, 1997; Redondo and Morris, 2011; Figure 1). This tagging phenomenon has also been identified in relation to memory, called instead behavioral tagging, where weak memories can become long-term memories when associated with a strong learning experience which would elicit this central gene response (Bear, 1997; Ballarini et al., 2009; Lesburguères et al., 2011; Redondo and Morris, 2011; Dunsmoor et al., 2015; Nomoto et al., 2016). In addition to the STC mechanisms, an "inverse tag" (Okuno et al., 2012) mechanism and a "cross-tagging" (Sajikumar and Frey, 2004; Sajikumar and Korte, 2011) mechanism have also been identified which allows for the depotentiation or depression of non-potentiated synapses (Figure 1). This range of "tags" can be set after L-LTP induction, increasing the diversity of mechanisms in which newly synthesized proteins may be involved (Frey and Frey, 2008; Okuno et al., 2012). Indeed, newly synthesized proteins induced by L-LTP induction can allow for the induction of L-LTD after stimulation that would normally only induce E-LTD (Sajikumar and Frey, 2004; Sajikumar et al., 2007), further corroborating the idea that the gene expression and protein synthesis elicited by L-LTP induction is generalized to many plasticity mechanisms (Kelleher et al., 2004; Sajikumar and Frey, 2004; Sajikumar et al., 2007).

Some PRPs related to L-LTP and L-LTD have been identified (Figure 1). The PKC isoform $\mathrm{PKM} \zeta$ has been proposed as one of the key PRP's involved in STC and has been shown to be essential to the maintenance of L-LTP and LTM (Sajikumar et al., 2005; Sajikumar and Korte, 2011; Tsokas et al., 2016) via an interaction with a CaMKII dependent tag at potentiated synapses (Sajikumar et al., 2007; Figure 1). BDNF is also associated with structural changes at potentiated synapses via STC (Barco et al., 2005; Sajikumar and Korte, 2011), as well as via activation of the trkB receptor (Korte et al., 1998) specifically at the synapse which has been potentiated (Harward et al., 2016). However, BDNF also appears to be involved in a cross-tagging mechanism which targets PRPs to synapses at which LTD has been induced (Sajikumar and Korte, 2011; Figure 1).

The role of Arc in learning and LTP has been thoroughly reviewed (Shepherd and Bear, 2011; Minatohara et al., 2015). Expression of the IEG Arc increases rapidly after L-LTP induction (Link et al., 1995; Lyford et al., 1995; Steward et al., 1998; Steward and Worley, 2001; Messaoudi et al., 2007; Ryan et al., 2011; Yilmaz-Rastoder et al., 2011) and plays a role in the structural rearrangement of synapses, in particular the endocytosis of $\alpha$-amino-3-hydroxy-5-methyl-4isoxazolepropionic acid (AMPA) receptors (Chowdhury et al., 2006). Inhibition of Arc expression $2 \mathrm{~h}$ after LTP induction causes LTP to rapidly decay to baseline (Messaoudi et al., 2007) and inhibition of Arc prior to LTP induction can restricts its persistence (Guzowski et al., 2000). Further, in mice in which the Arc gene has been knocked out (ArcKO) the magnitude of LTP induced in enhanced, but LTP cannot persist and the animals have impaired LTM (Plath et al., 2006). However, it is not clear if Arc is directly involved in the potentiation of synapses as recent work has shown that by interacting with an inverse tag set at inactive synapses by calcium/calmodulin-dependent protein kinase II $\beta$ (CaMKII $\beta$ ), Arc removes AMPA receptors containing GluA1 subunits, thereby depotentiating those synapses (Okuno et al., 2012; Figure 1). Further, Arc has been shown to be critical to the pruning, or elimination, of dendritic spines after learning (Nakayama et al., 2015; Figure 1). Intriguingly, it has also recently been found that $A r c$ can form virus like structures, which encapsulate RNA (Pastuzyn et al., 2018). Neurons have been shown to be capable of taking up these capsids, along with the mRNA contained within (Pastuzyn et al., 2018). This suggests that Arc may, in addition to synaptic weakening, enable communication between neurons and thus, though Arc is critical to the maintenance of potentiated synaptic strength after LTP induction, whether it is actually involved in the structural changes at the potentiated synapses is unclear.

One of the most critical and well-studied regulators of gene expression associated with L-LTP and LTM is the constitutively expressed transcription factor (TF) cAMP response element binding protein (CREB) (Bourtchuladze et al., 1994; Guzowski and McGaugh, 1997; Figure 1). CREB is phosphorylated (pCREB) immediately upon LTP induction, learning or cell firing and leads to an increase in the expression of IEGs (Bito et al., 1996; Deisseroth et al., 1996; Impey et al., 1998; Davis et al., 2000; Benito and Barco, 2010; Benito et al., 2011; Sajikumar and Korte, 2011; Figure 1). It is interesting to note that CREB has also been shown to drive increases in intrinsic excitability (Lopez de Armentia et al., 2007; Zhou et al., 2009). Conversely, inhibition of CREB decreases excitability and the induction of L-LTP (Jancic et al., 2009). Learning alone has also been shown to increase excitability (Moyer et al., 1996; McKay et al., 2009) which serves as a means of linking similar learning experiences, and their underlying engrams, which occur within close temporal proximity ( $<5$ h) (Cai et al., 2016). Indeed, overexpressing CREB has been shown to increase the likelihood of affected neurons being incorporated into an engram (Han et al., 2007; Zhou et al., 


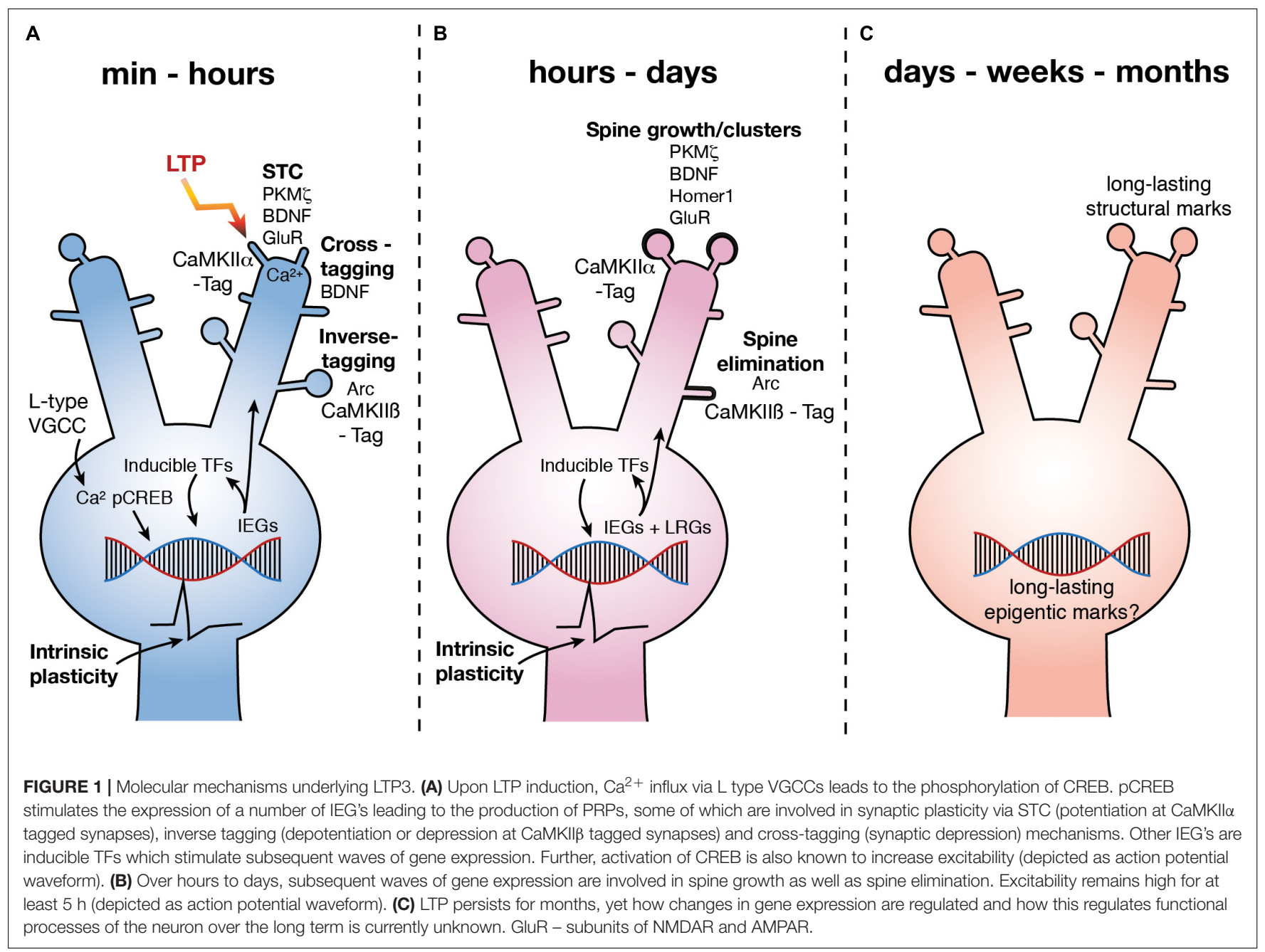

2009). Further, some genes regulated by the induction of LTP3 in vivo, such as KCNC2, KCNMA1, and CACNG8 encode proteins that regulate excitability (Ryan et al., 2011).

The above evidence indicates that genes that are upregulated by the induction of L-LTP lead to structural and functional changes at both potentiated synapses (via STC), as well as weakened synapses (via inverse or cross-tagging) and may play a role in altering intrinsic excitability. Further, as cell activity alone can drive IEG expression, and LTP3 specifically involves $\mathrm{Ca}^{2+}$ influx at the soma, the IEG response may also allow for generalized, cell-wide modifications (Figure 1). As a given neuronal ensemble will undergo periods of reactivation and subsequent plasticity, this seemingly broad, non-specific response questions whether the connectivity of an established engram is vulnerable to long-term alteration during periods of heightened gene transcription.

\section{IEGs Are Critical but Insufficient to Maintain L-LTP}

The rapid induction of IEG transcription factor expression has long been associated with persistent LTP. Indeed, when persistent LTP is induced in vivo in the dentate gyrus (Abraham et al., 1993), there seems to be a clear correlation between stimulus intensity and IEG expression as well as between stimulus intensity and LTP persistence. There is not, however, a clear relationship between IEG expression and LTP persistence. In response to high frequency electrical stimulation, the expression of IEGs has been shown to increase, with the level of expression generally corresponding to the number of stimulus trains given. Little change is seen after 10 or 20 brief trains, but with 30 trains and above there is a significant increase in expression of transcription factors, zif/268 (egr1), c-jun and junB. This coincides with a switch from LTP1 and LTP2 to LTP3 induction (Abraham et al., 1993). However, though 10 trains are insufficient to induce LTP3, 50\% of the tested samples did show some increase in the expression of the IEG Zif/268 (Abraham et al., 1993). After 50 trains, all hippocampi showed increased expression of Zif/268 even though only $73 \%$ showed LTP3 (Abraham et al., 1993). Further, the IEG $c$-fos has also been associated with LTP3 induction but its expression is not reliably altered by all induction paradigms that do induce LTP3 (Dragunow et al., 1989). Thus, although changes in IEG expression are indicative of the induction of persistent plasticity, 
we speculate that IEGs such as Zif/268 are part of the plasticity transcriptome which alters connectivity and excitability but does not regulate the persistence of LTP per se. Therefore, the question remains: what regulates the persistence of LTP and memory? To answer this question it is fundamental to consider the stage of LTM being investigated.

\section{MAKING L-LTP AND MEMORIES PERSIST}

The consolidation of LTP and LTM takes considerably longer than the few hours generally studied in vitro and in vivo (Dudai and Eisenberg, 2004). Numerous experiments have shown LTM to be dependent upon additional transcription- and translation-dependent stages occurring at $12-18 \mathrm{~h}$ and $24 \mathrm{~h}$ after learning, respectively (Bekinschtein et al., 2007, 2010; Katche et al., 2010). Importantly, infusion of a transcription inhibitor $24 \mathrm{~h}$ after learning had no effect if LTM was tested 2 days later, but LTM was significantly impaired if tested at 7 days (Katche et al., 2010). Thus, fundamental elements of the consolidation process occur at distinct times following the initial stimulation.

\section{Extended Timeframe of Gene Regulation After L-LTP Induction and Learning}

Brain Derived Neurotropic Factor (BDNF) has been identified as a potential regulator of a subsequent wave of transcription and translation, after the initial IEG response to learning (Bekinschtein et al., 2007, 2008). Weak learning, which would not normally lead to LTM, could be transformed to LTM by the application of BDNF $12 \mathrm{~h}$ after learning (Bekinschtein et al., 2008). Further, BDNF has been shown to be critical for a second wave of expression of the IEGs $c$-Fos, Zif/268 (Bekinschtein et al., 2007) and $\operatorname{Arc}$ (Nakayama et al., 2015) after learning (Figure 1). Interestingly, in the case of $A r c$ this second wave of transcription may underlie the selective pruning of small mushroom spines, as described above, which is essential to the activation of the engram upon longer term (7 days) but not shorter term (2 days) recall (Nakayama et al., 2015). As discussed above, the ARCCaMKII $\beta$ interaction can decrease synaptic AMPAR and thus synaptic drive, and CaMKII $\beta$ has also been shown to be critical to long term (10 days) but not short term (1 day) recall (Cho et al., 2007).

\section{Ongoing Gene Expression After LTP3 and Learning - A Maintenance Transcriptome?}

Many of the IEGs that were first identified as regulated after L-LTP induction are themselves inducible TFs (Sheng et al., 1991) and sequential activation of TFs after LTP3 induction in vivo has been identified (Williams et al., 2000). This alone suggests that the L-LTP associated transcriptional response is not temporally confined to the proximity of the stimulus. Indeed, extending these early studies, recent transcriptome-wide approaches have confirmed on-going, complex and dynamic changes in gene expression over at least $24 \mathrm{~h}$ post-LTP3 induction in vivo in the dentate gyrus (Ryan et al., 2012). Furthermore, as described above, subsequent waves of gene expression and protein synthesis have been identified 12 and $24 \mathrm{~h}$ after learning, both of which are critical to LTM (Bekinschtein et al., 2008, 2010, Katche et al., 2010, 2012) and, a recent study has shown that sustained neuronal activity, or sustained sensory input, induces waves of different gene expression that are strikingly similar to those which are seen after LTP induction or learning (Tyssowski et al., 2018). However, due to limited information about ongoing gene expression after learning, we focus here on LTP.

Using network analysis of the genes regulated over time after LTP3 induction in vivo (Ryan et al., 2012) our group has tried to understand the relationship of altered gene expression to the persistence of LTP. Such analyses aim to derive the role of co-operatively acting groups of genes and identify center hub molecules proposed to play key roles within a given network and we have shown that these hubs are critical to the stability of these gene networks (Nido et al., 2015).

Analysis of the networks regulated rapidly $(20 \mathrm{~min})$ post-LTP3 induction suggest that these genes are heavily involved in gene transcription, cell growth and development (Ryan et al., 2011, 2012), matching the restructuring of connectivity and ongoing regulation of gene expression described above. By $5 \mathrm{~h}$ post-LTP induction the main function of the genes regulated were calcium dynamics, G-protein signaling and negative regulation of gene expression, functions that regulate the induction of LTP and thus, would affect the induction of subsequent plasticity (Ryan et al., 2012). However, by $24 \mathrm{~h}$ the genes regulated were found to be involved in the inhibition of protein synthesis and epigenetic negative regulation of gene expression. Indeed, in contrast to the earlier times, a general downregulation of gene expression was seen at $24 \mathrm{~h}$ (Ryan et al., 2012). To further explore this novel observation, we tested the relevance of the LTP-associated gene networks using random Boolean network simulations. We found that the stability of the early network was crucially dependent on the presence of the key hub molecule, egr-2 (Nido et al., 2012) and that the 24 network was markedly more stable that the early networks. Further, we also found that the architecture exhibited by a control and the $24 \mathrm{~h} \mathrm{LTP} \mathrm{co-expression} \mathrm{networks} \mathrm{fit} \mathrm{well} \mathrm{to} \mathrm{a}$ scale-free distribution, known to be robust against perturbations (Nido et al., 2015), remarkably mirroring the stability of LTP and memory. Together these observations support the novel hypotheses that the waves of gene expression observed following LTP3 play divergent roles over time and that there may be a shift in the threshold for plasticity related gene expression over time after LTP3 induction, underpinned by epigenetic modifications.

\section{A ROLE FOR THE INHIBITION OF PLASTICITY IN THE MAINTENANCE OF LTP AND MEMORY}

An engram is initially labile and susceptible to disruption but is then consolidated and made resistant (Dudai, 1996; Frankland and Bontempi, 2005; Medina et al., 2008; Alberini and Kandel, 2015). The extinction of a previously learned fear behavior is a commonly used tool that can probe the structural stability, and 
integrity, of an engram. However, much debated has focused on whether the original fear engram is altered during fear extinction, or if the fear extinction training creates an entirely new engram. A compelling study has recently shown a positive correlation between the number of cells activated during fear extinction that were part of the original fear memory engram and the efficiency of the new fear extinction training (Khalaf et al., 2018). This suggests, at least in part, that the integrity of the original fear engram was detrimentally effect by the recruitment of those cells to the new memory, i.e., the fear memory was diminished or lost (Khalaf et al., 2018). Thus, some break that inhibits plasticity within a neuron incorporated into an engram would be advantageous to the protection of said engram. Indeed, in some conditions once LTP has been induced or learning has occurred, further plasticity, even at synapses that were not potentiated, is blocked or occluded (Abraham et al., 2001; Whitlock et al., 2006; Hulme et al., 2012; Nabavi et al., 2014). In the motor cortex this occlusion can be maintained for at least 23 days (Rioult-Pedotti et al., 2007). This increase in the threshold for plasticity may allow the engram to persist over that time by blocking other inputs from making competing alterations. Indeed, sufficiently strong competing inputs have been shown to detrimentally affect the persistence of LTP. Inducing LTP3 at one set of synapses on the DG granule cells can cause a previously established LTP3 at a different set of synapses to decay rapidly (Abraham et al., 2006). These results suggest that subsequent LTP induction may be detrimental to previously established LTP.

\section{Reactivating an Engram Induces a Labile State That Can Disrupt Its Connectivity}

Reactivation of the engram can make it labile again and allow it to be updated with new information (Ramirez et al., 2013, 2015; Khalaf et al., 2018). Over time, after an engram has been updated, it can be reconsolidated, a process which is dependent upon very similar mechanisms to learning and consolidation, including NMDAR receptor activation, protein synthesis and gene expression, and seemingly works by STC mechanisms (Przybyslawski and Sara, 1997; Alberini, 1999; Nader et al., 2000; Nader and Hardt, 2009; Cassini et al., 2013). Surprisingly though, with regards to LTP, reactivating a pathway $24 \mathrm{~h}$ after LTP had been induced in that pathway, using the same stimulation protocol, the expression of IEGs is significantly less than that after the initial LTP induction (Abraham et al., 1995). This suggests that IEG expression is in some way dampened by prior activity. Support for this comes from the visual cortex, where plasticity mechanisms are severely attenuated after what is described as the "critical period" is closed (Hubener and Bonhoeffer, 2014). Dampened expression of the IEG Arc is fundamental to the reduced plasticity and it can in fact be rescued by simply increasing levels of Arc in the region (Jenks et al., 2017). In addition, an epigenetic break on transcription (see Section 5) has been shown to limit the lability of a stable memory and, if alleviated, long-term plastic changes can be made to an established engram (Gräff et al., 2014). Together, these studies imply that different activation thresholds for gene expression exist and accordingly, reactivation of an engram may induce a different gene expression response than that induced during the initial experience (Harrow et al., 2012). Further, it is possible then that decreasing the efficiency of the signaling pathways or engaging an epigenetic mechanism to dampen gene expression could achieve this transcription response.

\section{Genes Which Negatively Regulate Plasticity Are Themselves Upregulated 24 h Post-LTP: A Proposed Maintenance Transcriptome}

The TF, nuclear factor kappa-light-chain-enhancer of activated B cells (NF-кB), is the central hub of one of the most important networks of genes found to be regulated $24 \mathrm{~h}$ post-LTP3 (Ryan et al., 2012). NF- $\mathrm{BB}$ is activated after LTP3 induction (Freudenthal et al., 2004), is critical to memory reconsolidation, in particular via epigenetic regulation of gene expression (Lubin and Sweatt, 2007), and the maintenance of memory (Levenson et al., 2004a ; Dash et al., 2005; Freudenthal et al., 2005). The network, which largely contained upregulated genes, includes the Tnf receptor, MAPK13 and MAPKAPK3 (Ryan et al., 2012). These genes are involved in the TNF $\alpha$ - p38 MAPK pathway, which has previously been implicated in negative modulation of LTP induction (Gisabella et al., 2003; Butler et al., 2004; Izumi et al., 2008; Figure 2).

A second important network of genes regulated $24 \mathrm{~h}$ post-LTP3 induction, involved a considerable number of downregulated genes, with a central hub of histone deacetylase 2 (HDAC2) which is itself upregulated (Ryan et al., 2012). Interestingly, histone deacetylase 1 (HDAC1) was also part of this network but was instead downregulated, though it was upregulated and central to the strongest network of genes regulated $5 \mathrm{~h}$ post-LTP induction (Ryan et al., 2012). Histone acetylation is an important epigenetic mechanism that controls gene expression and is regulated via histone acetyltransferases (HATs) and deacetylation via histone deacetylases (HDACs), which have been strongly associated with memory, LTP and memory-related diseases such as Alzheimer's disease (Levenson et al., 2004b; Guan et al., 2009; Gräff et al., 2012). HATs acetylate lysine residues on histone tails, creating an environment that is permissive to gene transcription by allowing TFs access to their target genes (Gräff et al., 2011; Stilling and Fischer, 2011). HDACs remove acetyl groups from lysine residues on histone tails, thereby decreasing the permissiveness to gene transcription and are thus believed to be negative regulators of gene expression, L-LTP induction and learning (Gräff et al., 2011; Stilling and Fischer, 2011). Due to the central, high-level control of gene expression which epigenetic mechanisms employ, and the fact that we found HDAC1 and 2 to be regulated by the induction of LTP3, we propose that the change in HDAC expression we identified may be indicative of a metaplastic rise in the threshold for plasticity related gene expression. In conjunction with signaling pathways such as the p38 - MAPK discussed above, this general inhibition of plasticity may protect the structure and function of the cell involved in the engram (Figure 2). It is important to note that while we have focused this hypothesis on HDAC1 and 2 due to our findings, numerous other HDAC family 


\section{LTP3}

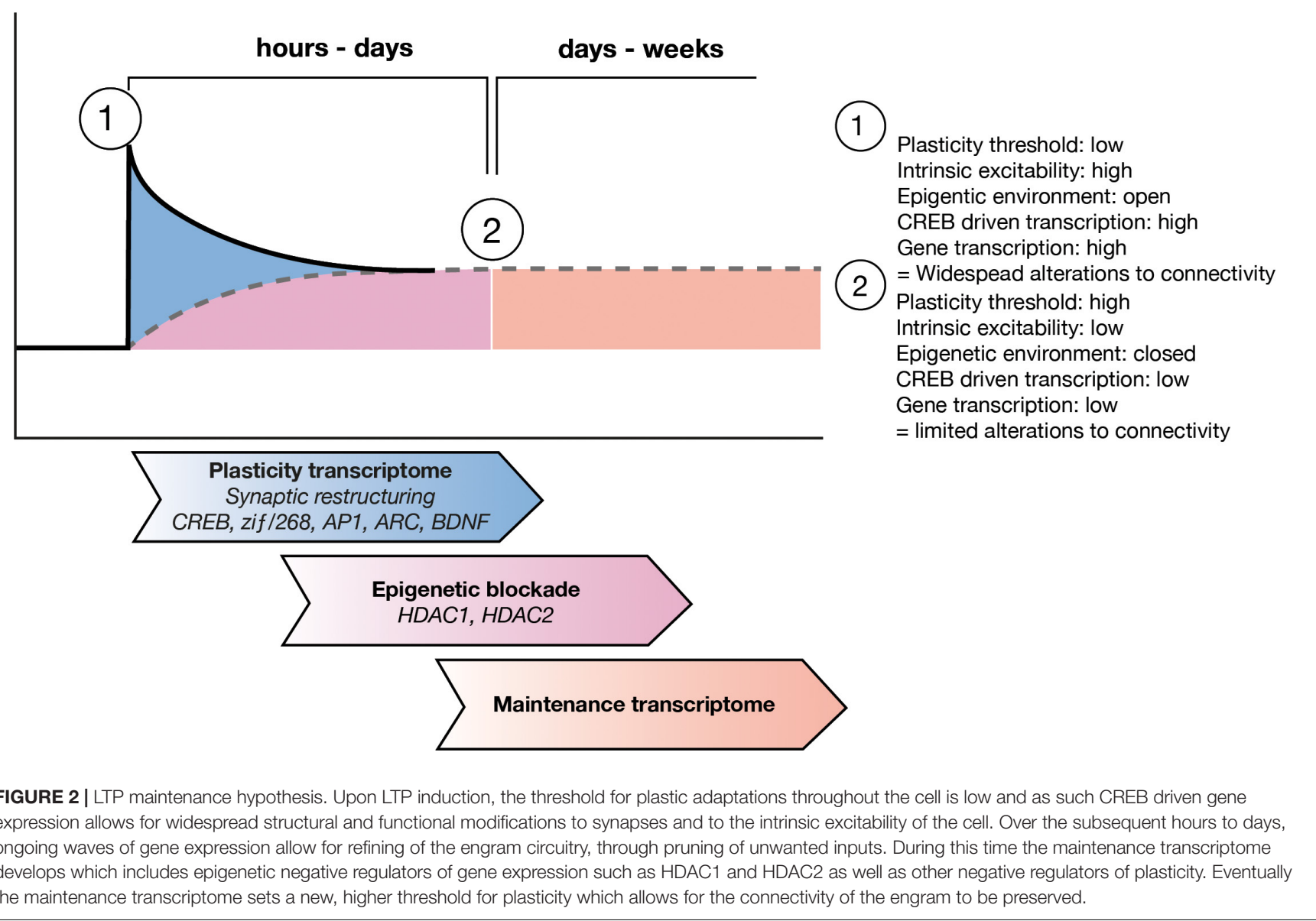

members have been found to be important for learning, memory and synaptic plasticity (Mahgoub and Monteggia, 2014; Penney and Tsai, 2014).

\section{A ROLE FOR HISTONE ACETYLATION AS AN EPIGENETIC METAPLASTICITY MECHANISM TO REGULATE ENGRAM MAINTENANCE}

\section{A Permissive Epigenetic State Coincides With the Induction of L-LTP and Learning}

The vital role of gene transcription for the persistence of LTP and memory leads to the hypothesis that an epigenetic environment that is permissive to gene transcription would coincide with periods of heightened gene transcription. Upon learning, histone acetylation is transiently increased (Alarcón et al., 2004; Wood et al., 2005; Chwang et al., 2007; Vecsey et al., 2007; Miller et al., 2008; Gräff and Tsai, 2013) through an NMDAR and ERK-dependent pathway (Levenson et al., 2004b). Further, upon repeated learning experiences, acetylation is also increase within an hour (Bousiges et al., 2010). Aged animals with LTM impairments do not display an increase in acH4K12 after fear conditioning, which occurs transiently in control animals (Peleg et al., 2010). Though only correlational, this suggests that at least a brief increase in acetylation may be critical to the formation of LTM. Additionally, evaluation of the epigenetic environment after neuronal activity alone has shown that genes that respond rapidly to activity have a more open, permissive chromatin state and have more pre-engaged transcriptional machinery than those that respond more slowly or only to long-durations of activity (Tyssowski et al., 2018). Interestingly, this group of rapidly responsive genes also depend on the activation of the MAPK/ERK pathway (Tyssowski et al., 2018).

\section{Creating a Permissive Epigenetic Environment Promotes Plasticity}

Artificially increasing histone acetylation has been shown to promote L-LTP. Incubation of hippocampal slices with the HDACi trichostatin A (TSA) or sodium butyrate (NaBut) increases acetylation and facilitates both the induction and maintenance of LTP (over $3 \mathrm{~h}$ ) in a transcription-dependent 
manner (Levenson et al., 2004b). However, the enhanced magnitude of LTP upon induction suggests that HDAC inhibition itself must drive transcription under basal conditions, i.e., prior to, rather than only in response to, LTP induction. Further, application of TSA to slice preparations, prior to and throughout recordings, has been shown to promote the induction of L-LTP from stimuli that would normally only induce E-LTP (Vecsey et al., 2007). Again, this was found to be critically dependent upon transcription, in particular CREB driven gene expression (Vecsey et al., 2007).

Enhanced learning is also evident after increasing acetylation. Rats exposed to the HDACis vorinostat or TSA show enhanced fear conditioning and object recognition when tested $24 \mathrm{~h}$ post-learning (Vecsey et al., 2007; Stefanko et al., 2009; Fujita et al., 2012). Further, modified animals in which HDAC2 is knocked out (HDAC2KO) display enhanced fear conditioning and spatial learning at $24 \mathrm{~h}$, whereas in animals that over-express HDAC2 (HDAC2OE) animals display the opposite (Guan et al., 2009). Indeed, vorinostat is also known to enhance fear extinction $24 \mathrm{~h}$ after injection (Fujita et al., 2012) and both TSA and vorinostat seemingly lead to this enhancement via increased acetylation and pCREB driven gene expression (Vecsey et al., 2007; Fujita et al., 2012). However, although HDAC2KO animals have enhanced contextual conditioning at $24 \mathrm{~h}$ post-learning, this is not retained at later time points (Morris et al., 2013). In fact, cued fear conditioning was not enhanced at $24 \mathrm{~h}$ and was actually decreased 48 and $72 \mathrm{~h}$ after learning. This effect has been attributed to enhanced fear extinction (Morris et al., 2013) though it could also be argued that LTM was inhibited. Finally, increasing acetylation simply by exposing animals to an enriched environment can restore learning capabilities in the ck-p25 transgenic mouse model of neurodegenerative diseases (Fischer et al., 2007).

\section{Decreased Histone Acetylation Restricts Plasticity}

In accordance with enhanced LTP in a permissive epigenetic environment, a restricted epigenetic environment is detrimental to L-LTP. The CREB co-activator CBP functions as a HAT and therefore increases acetylation. In hippocampal slices from heterozygous CPB knockout mice $\left(\mathrm{cbp}^{+/-}\right)$, E-LTP was not affected but L-LTP was significantly diminished (Alarcón et al., 2004). This reduction was associated with a reduced level of acetylation. By reducing HDAC activity using the HDACi Suberoylanilide Hydroxamic Acid (SAHA) prior to LTP induction, presumably thereby restoring balance between HAT and HDAC activity, the magnitude of L-LTP was restored to control levels (Alarcón et al., 2004). Together, these data suggest that at the time of learning or LTP induction, the transcription of genes necessary for persistent LTP or memory is regulated by an increase in histone acetylation. This epigenetic state, which is permissive of gene transcription and formation of LTM, may also exert a paradoxical side effect where the previous connectivity of a given neuron is made vulnerable to disruption at this early stage.

The $\mathrm{cbp}^{+/-}$mice (Alarcón et al., 2004) as well as mutant mice which lack the HAT ability of CBP $\left(\mathrm{CPB} \mathrm{HAT}{ }^{-}\right.$) (Korzus et al., 2004), and mice which lack the CREB isoforms $\alpha$ and $\Delta$ (Vecsey et al., 2007), all show impaired LTM formation. Intraventricular infusion of the HDACi SAHA increased acetylation and recovered memory to control levels in the $\mathrm{cbp}^{+/-}$ mice (Alarcón et al., 2004). However, the impairment seen in the CREB mutants could not be restored to the same degree (Vecsey et al., 2007). This suggests that, as in LTP experiments, TSA treatment must work via CREB to enhance learning. Thus, the recovered acetylation and memory in $\mathrm{cbp}^{+/-}$animals, in response to the HDACi, seemingly overcame the limited HAT capabilities either by driving CREB dependent transcription and/or by decreasing HDAC activity (Alarcón et al., 2004; Vecsey et al., 2007). Interestingly, the CPB HAT ${ }^{-}$mice showed significant impairment in recognition and spatial memory tasks. However, this impairment could be rectified by recovery of HAT activity or by more intensive training (Korzus et al., 2004). Similarly, $\mathrm{cbp}^{+/-}$animals that were repeatedly trained in the spatial memory task had no deficits (Alarcón et al., 2004). This suggests that the permissive, open state of the chromatin can be brought about via a number of mechanisms regulating the balance of HAT and HDAC activity. However, it is achieved, increased acetylation is needed to open the chromatin nearby plasticity related genes.

\section{HDAC2 Negatively Regulates the Capacity for Structural Plasticity of Synapses}

In support of the hypothesis that the plasticity transcriptome underpins synaptic restructuring, knock-out of the Hdac2 gene (HDAC2KO) causes long-term structural modifications to synapses. Slices from HDAC2KO mice display decreased synaptic transmission (Morris et al., 2013), while in another set of experiments using $\mathrm{HDAC} 2 \mathrm{KO}$ mice, despite an overall increase in spine density, a decreased number of mushroom spines was found (Guan et al., 2009). On the other hand, spine density was decreased in Hdac2 over-expressing animals (HDAC2OE) (Guan et al., 2009) and in a disease model which leads to Hdac2 over-expression (Gräff et al., 2012). Thin spines are believed to potentiate into mushroom spines upon LTP induction, a process hypothesized to be a structural trace of memory formation (Bourne and Harris, 2007). Although it has not been conclusively shown, the combination of decreased synaptic transmission and fewer mushroom spines in HDAC2KO mice, despite greater overall spine density, suggests that the existing spines contain silent or non-potentiated synapses with fewer AMPARs (Matsuzaki et al., 2004). Increasing the number of silent spines has previously been shown to enhance LTP induction (Arendt et al., 2013), presumably because he number of spines at which LTP can be induced is increased. Thus, these results would predict that $\mathrm{HDAC} 2 \mathrm{KO}$ or $\mathrm{KD}$ animals should have enhanced L-LTP induction. Indeed this is the case, as L-LTP can be induced with mild stimulation, which would normally only induce E-LTP, in hippocampal slices from HDAC2KO mice (Guan et al., 2009; Morris et al., 2013) and L-LTP could not be induced in HDAC2OE animals (Guan et al., 2009) or in a disease model which leads to HDAC2 over-expression (Gräff et al., 2012). Together, these results suggest that HDAC2 negatively regulates 
the expression of genes associated with spine growth and synapse formation, and this may lead to enhanced learning. Intriguingly, the lack of mushroom spines in the HDAC2KO mice suggests that this may be at the expense of maintaining LTP and LTM.

\section{Evidence of HDAC1 and 2 Regulation of the Plasticity Transcriptome}

With the promotion of structural plasticity at spines and synapses, at the expense of maintenance, it would be expected that HDAC2 would negatively regulate genes related to this process. The level of acetylation and HDAC2 present at the promoter region of a number of important plasticity and neuronal activity related genes are inversely related in HDAC2OE and $\mathrm{KO}$ animals (Guan et al., 2009). Most importantly, genes required for structural rearrangement during learning and in synapse formation (such as CaMKIIa and PKM regulated by HDAC2. Concomitant mRNA expression of these genes has also been identified (Guan et al., 2009). Further, in an Alzheimer's disease model which had increased HDAC2 expression, genes involved in structural rearrangement of synapses such as Arc and Homer1 were suppressed, as were genes related to synapse formation such as Glur1, Glur2, Nr2a, Nr2b and Syp (Gräff et al., 2012). Together, these observations support the learning and LTP results suggesting HDAC2's negative regulation of learning and plasticity, rather than maintenance per se. Surprisingly, HDAC2OE animals also showed increased acetylation at the promoter region of some plasticity related genes (Guan et al., 2009). While regulation of HDAC2 levels did, in most cases, have expected results on acetylation, there were significant exceptions to this rule (Guan et al., 2009). However, a genome-wide analysis of HDAC2 expression has not been performed and as such, the specificity of HDAC2 regulation of plasticity related genes cannot be concluded at this time.

Histone deacetylase 1 (HDAC1) overexpression has been shown to lead to either no change in the acetylation at the promoter region of most genes investigated, or lead to an increase in acetylation of some plasticity related genes (Guan et al., 2009). Confusion around the implications of this is exacerbated by the finding that the loss of HDAC1 activity through a neurodegenerative disease model and through knockdown by siRNA resulted in neuronal cell death with an associated increase in expression of genes related to cell cycle (Kim et al., 2008). These effects could be ameliorated by overexpression of HDAC1 (Kim et al., 2008). Further, HDAC1 has been shown to gradually accumulate at the promoter region of $c$-Fos, over 5 days of fear extinction training, which parallels a gradual decrease in c-Fos expression over the same time course (Bahari-Javan et al., 2012). Although these results highlight a mostly tight negative regulation of genes involved in plasticity and learning by HDAC2, there are clear exceptions to this in mRNA expression and acetylation and cast some doubt over the dogma that HDACs negatively regulate acetylation, gene expression and LTM.

\section{Ongoing Epigenetic Regulation}

The evidence presented so far supports the notion that HDAC2 in particular regulates the expression of genes involved in structural rearrangements of synapses in the early time period after learning or the induction of L-LTP. However, as described above, there is evidence that dynamic gene expression occurs for at least $24 \mathrm{~h}$, such as via BDNF driven transcription (Bekinschtein et al., 2008). Therefore, dynamic regulation of gene expression over this time should also occur. Recently it has been shown that Arc gene expression is driven by different response elements within the promoter region of the gene (Fukuchi et al., 2015). Specifically, it was found that the synaptic activity-response element (SARE), located $-7 \mathrm{kbp}$ upstream of the Arc transcription start site (TSS), was responsive to NMDA, BDNF and FGF2 but that a proximal promoter region, -1679 from the TSS was only responsive to BDNF and FGF2 (Fukuchi et al., 2015). Upon induction of LTP, presumably through NMDAR driven transcription and thus derived from activation of the more distal response element, Arc has been shown to move out of the nucleus toward active dendrites (Steward et al., 1998, 2014). However, in neuronal cell culture after NMDAR activation, ARC has been shown to localize in the nucleus and interact with Tip60, a HAT, leading to increased acH4K12 (Wee et al., 2014). The second wave of Arc expression, described above as critical to LTM, is driven by BDNF (Nakayama et al., 2015). The proximal promoter region of $A r c$, regulated by BDNF, is under HDAC1 control (Fukuchi et al., 2015). Interestingly, it was found that the HDACi TSA could only enhance the transcription of Arc by this proximal promoter region (Fukuchi et al., 2015). In striking contrast, TSA actually inhibited NMDA-driven expression (Fukuchi et al., 2015). This suggests that HDACi driven gene expression is changing the plasticity-induced transcriptome and, therefore, the tight control of transcription may be lost. As Arc can be regulated by HDAC2 (Gräff et al., 2012) and HDAC1 (Guan et al., 2009; Fukuchi et al., 2015), there may be waves of Arc expression, potentially driven by different promoters and regulated by different epigenetic mechanisms. If the expression of one gene is dynamically regulated by different signaling mechanisms and under the control of different HDACs over time, there is potential for other genes to have similar capacities and thus tight temporal regulation of the epigenome may be extremely important.

\section{HDAC Activity as a Metaplastic Protector of Engrams}

The critical question for our hypothesis is whether enhancing a permissive chromatin state destabilizes previously established engrams. Ocular dominance columns of the visual cortex are well-characterized examples of highly stable neuronal networks. After a critical period of plasticity during early post-natal days, the visual cortex becomes rigid and signaling pathways which would normally induce the expression of plasticity genes are unable to do so (Putignano et al., 2007). Evidence suggests that though the intracellular pathways involved are still fully functional, the gene expression response is suppressed, and this suppression is regulated by either increased HDAC activity, or by decreased HAT activity (Putignano et al., 2007; Baroncelli et al., 2016). Increasing histone acetylation with an HDACi can lead to the destabilization of the neuronal networks forming the ocular dominance columns 
and allow for restructuring and updating of the circuitry (Putignano et al., 2007; Lennartsson et al., 2015; Baroncelli et al., 2016).

Updating of a conditioned fear response, much like restructuring of ocular dominance columns, similarly tests the strength and maintenance of the original connectivity related to a fear response. Indeed, a fear memory, $24 \mathrm{~h}$ post-learning, is labile and can be readily and persistently updated with fear extinction training (Gräff et al., 2014). In conjunction with this, acetylation of $\mathrm{H} 3 \mathrm{~K} 9 / \mathrm{K} 14$ is significantly increased $1 \mathrm{~h}$ after recall of this recently formed memory (Gräff et al., 2014). However, with a consolidated, 30 day old fear memory, there is no such increase in acetylation upon recall, and the memory cannot be persistently altered by the same extinction protocol (Gräff et al., 2014). This suggests negative regulation of acetylation coincides with negative regulation of genes involved in the structuring of connectivity, described above. Indeed, inhibiting HDAC2 before the recall of the 30 day old memory allows for IEGs such as $A r c$ and c-Fos to be expressed in response to recall, and for a persistent alteration to the memory to be made (Gräff et al., 2014).

Histone deacetylase 1 (HDAC1) has been shown to positively regulate fear extinction (Bahari-Javan et al., 2012), seemingly opposite to the idea that negative regulators of gene expression negatively regulate LTM. Acute overexpression of HDAC1 enhanced fear extinction, however, it had no effect on working memory, novel object recognition or contextual fear conditioning (Bahari-Javan et al., 2012). A gradual decrease in c-Fos expression after each fear extinction trial is shown to correspond to an increase in $\mathrm{HDACl} 1$ and a decrease in acH3K9 at the promoter region of the $c$-Fos gene at the same time points (Bahari-Javan et al., 2012). Thus, HDAC1 appears to negatively regulate the expression of $c$-Fos, altering the reconsolidation of the engram to decrease the fear response. These examples suggest increased regulation of histone acetylation does play a role in maintaining consolidated memories over time by raising the threshold needed to be reached for plasticity related gene expression to occur.

Evidence supports another epigenetic transcriptional repressor as a maintenance mechanism LTM (Miller et al., 2010). Long-term changes in methylation of GC-rich $\mathrm{CpG}$ islands in the dorsomedial prefrontal cortex has been shown to be critical to the maintenance of LTM (Miller et al., 2010). These changes were distinct from epigenetic changes in the hippocampus during the initial learning period and suggested to perhaps underlie state changes to the threshold for plasticity or to the ongoing synthesis of proteins that support potentiated synapses (Miller et al., 2010). Further, Webb et al., 2017 propose that histone methylation and DNA hydroxymethylation regulate the expression of specific genes during retrieval of recent vs. older memories in a region specific manners (Webb et al., 2017). There is also evidence for early changes in methylation state also correlate with expression of plasticity related genes after LTP induction in vivo (though in anesthetized animals) (Maag et al., 2017). Much like acetylation, how methylation plays a role in learning versus memory is still under discussion (Oliveira, 2016).
While most of the above information would suggest that HDACs negatively regulate gene expression, it has been shown that HDAC1 and 2 are recruited to active genes (Wang et al., 2009). Further, the HDACi TSA, which has been used in a number of experiments, has been shown to largely affect regions of the genome which were found to be enriched in acH4K9/K14 and trimethylated $\mathrm{H} 3 \mathrm{~K} 4(\mathrm{H} 3 \mathrm{~K} 4 \mathrm{me} 3)$ at basal levels and indeed these marks were a prerequisite for $\mathrm{H} 4$ hyperacetylation in response to TSA (Lopez-Atalaya et al., 2013). This indicates that the effect of TSA is restricted to regions of the genome that are already somewhat active. Together, these results suggest that HATs and HDACs must be working at the same promoter regions to regulate the balance of acetylation (Wang et al., 2009; Lopez-Atalaya et al., 2013). Finally, it is also important to remember that HDAC1 and 2, like other HDACs, have non-histone targets such as p53, E2F1, GATA4 and NF- $\kappa \mathrm{B}$, in particular the p65 subunit (Kelly and Cowley, 2013).

\section{SUMMARY}

Here, we have built on the evidence that L-LTP and LTM requires not only potentiation of synapses but also depotentiation or depression of neighboring synapses, and alterations to intrinsic excitability. We suggest that all of these changes occur together as a concerted response and are the result of a specific plasticity transcriptome, which produces gene products that make changes to the structure and function of the cell (Figure 2). However, we propose that the plasticity transcriptome does not underlie maintenance of structural changes involved in engram formation and thus, LTM. We hypothesize that there is also a maintenance transcriptome, particularly controlled by the action of HDAC1 and HDAC2 activity but other epigenetic regulators may also be involved, which acts to raise the threshold at which future activity can again induce the expression of the plasticity transcriptome, helping to ensure that the integrity of the engram is preserved (Figure 2).

Dynamic gene expression profiles play specific roles at different stages during the consolidation of L-LTP, LTM and the engram structure. In particular, IEGs related to the restructuring of synaptic connections upon learning or LTP induction seem to be strongly regulated by HDAC2. However, the profiles identified at later time points, particularly during the stabilization of the engram, have been less well studied. Three critical components must be investigated more thoroughly to test our hypotheses. First, the epigenetic state of cells involved in a given engram, at various time periods after learning needs to be established to determine if there is in fact an epigenetic identity of an engram. Secondly, subtype-specific HDACis must be identified, rather than relying on broad-spectrum HDACis that do not differentiate between HDAC1 and 2. Thirdly, the effects of HDAC inhibition on LTM and the persistence of LTP need to be assessed at stages later than $24 \mathrm{~h}$ post-learning. Together, these three components will then allow for testing of the stability of an engram in the face of new learning, and whether there is in fact an epigenetic 
metaplasticity mechanism involved in the maintenance of memory.

The determination to find memory-enhancing drugs which may aid in the treatment of neurodegenerative diseases in particular, such as HDACis, needs to be met with a thorough understanding of what underlies the long-term maintenance of memories in the first place. Systemic application of broad-acting inhibitors has the potential to create a highly plastic learning environment but may come at the expense of a stable, longterm storage environment. Thus, in a disease state in which reduced plasticity is a symptom, is recovering that plasticity always the best option for the health and survival of the cell in question? Regardless of the answer, understanding the learning and maintenance processes of memory, and why these may go awry in disease states, is critical for the specific targeting of treatments as well as for the basic understanding of brain function.

\section{REFERENCES}

Abdou, K., Shehata, M., Choko, K., Nishizono, H., Matsuo, M., Muramatsu, S.I., et al. (2018). Synapse-specific representation of the identity of overlapping memory engrams. Science 360, 1227-1231. doi: 10.1126/science.aat3810

Abraham, W. C. (2003). How long will long-term potentiation last? Philos. Trans. R. Soc. B Biol. Sci. 358, 735-744. doi: 10.1098/rstb.2002.1222

Abraham, W. C. (2008). Metaplasticity: tuning synapses and networks for plasticity. Nat. Rev. Neurosci. 9:387. doi: 10.1038/nrn2356

Abraham, W. C., and Bear, M. F. (1996). Metaplasticity: the plasticity of synaptic plasticity. Trends Neurosci. 19, 126-130. doi: 10.1016/S0166-2236(96)80018-X

Abraham, W. C., Dragunow, M., and Tate, W. P. (1991). The role of immediate early genes in the stabilization of long-term potentiation. Mol. Neurobiol. 5, 297-314. doi: 10.1007/BF02935553

Abraham, W. C., and Goddard, G. V. (1983). Asymmetric relationships between homosynaptic long-term potentiation and heterosynaptic long-term depression. Nature 305, 717-719. doi: 10.1038/305717a0

Abraham, W. C., Logan, B., Greenwood, J. M., and Dragunow, M. (2002). Induction and experience-dependent consolidation of stable long-term potentiation lasting months in the Hippocampus. J. Neurosci. 22, 9626-9634. doi: 10.1523/JNEUROSCI.22-21-09626.2002

Abraham, W. C., Mason, S. E., Demmer, J., Williams, J. M., Richardson, C. L., Tate, W. P., et al. (1993). Correlations between immediate early gene induction and the persistence of long-term potentiation. Neuroscience 56, 717-727. doi: 10.1016/0306-4522(93)90369-Q

Abraham, W. C., Mason-Parker, S. E., Bear, M. F., Webb, S., and Tate, W. P. (2001). Heterosynaptic metaplasticity in the hippocampus in vivo: a BCM-like modifiable threshold for LTP. Proc. Natl. Acad. Sci. U.S.A. 98, 10924-10929. doi: 10.1073/pnas.181342098

Abraham, W. C., Mason-Parker, S. E., Irvine, G. I., Logan, B., and Gill, A. I. (2006). Induction and activity-dependent reversal of persistent LTP and LTD in lateral perforant path synapses in vivo. Neurobiol. Learn. Mem. 86, 82-90. doi: 10.1016/j.nlm.2005.12.007

Abraham, W. C., Mason-Parker, S. E., Williams, J., and Dragunow, M. (1995). Analysis of the decremental nature of LTP in the dentate gyrus. Mol. Brain Res. 30, 367-372. doi: 10.1016/0169-328X(95)00026-O

Abraham, W. C., and Williams, J. M. (2003). Properties and mechanisms of LTP maintenance. Neuroscientist 9, 463-474. doi: 10.1177/1073858403259119

Abraham, W. C., and Williams, J. M. (2008). LTP maintenance and its protein synthesis-dependence. Neurobiol. Learn. Mem. 89, 260-268. doi: 10.1016/j.nlm. 2007.10.001

Akaneya, Y., Tsumoto, T., Kinoshita, S., and Hatanaka, H. (1997). Brain-derived neurotrophic factor enhances long-term potentiation in rat visual cortex. J. Neurosci. 17, 6707-6716. doi: 10.1523/JNEUROSCI.17-17-06707.1997

Alarcón, J. M., Malleret, G., Touzani, K., Vronskaya, S., Ishii, S., Kandel, E. R., et al. (2004). Chromatin acetylation, memory, and LTP are impaired in CBP+/-

\section{AUTHOR CONTRIBUTIONS}

All authors listed have made a substantial, direct and intellectual contribution to the work, and approved it for publication.

\section{FUNDING}

This work was supported by a University of Otago Doctoral Scholarship to MK.

\section{ACKNOWLEDGMENTS}

The authors thank Prof. W. C. Abraham and Dr. O. D. Jones for valuable revision of earlier drafts of the manuscript and Robbie $\mathrm{McPhee}$ for assistance with constructing the figures.

mice: a model for the cognitive deficit in Rubinstein-Taybi syndrome and its amelioration. Neuron 42, 947-959. doi: 10.1016/j.neuron.2004.05.021

Alberini, C. M. (1999). Genes to remember. J. Exp. Biol. 202, 2887-2891.

Alberini, C. M., and Kandel, E. R. (2015). The regulation of transcription in memory consolidation. Cold Spring Harb. Perspect. Biol. 7:a021741. doi: 10. 1101/cshperspect.a021741

Alger, B. E., and Teyler, T. J. (1976). Long-term and short-term plasticity in the CA1, CA3, and dentate regions of the rat hippocampal slice. Brain Res. 110, 463-480. doi: 10.1016/0006-8993(76)90858-1

Andersen, P., Sundberg, S. H., Sveen, O., Swann, J. W., and Wigstrom, H. (1980). Possible mechanisms for long-lasting potentiation of synaptic transmission in hippocampal slices from guinea-pigs. J. Physiol. 302, 463-482. doi: 10.1113/ jphysiol.1980.sp013256

Aniksztejn, L., and Ben-Ari, Y. (1991). Novel form of long-term potentiation produced by a K+ channel blocker in the hippocampus. Nature 349, 67-69. doi: $10.1038 / 349067 \mathrm{a} 0$

Arendt, K. L., Sarti, F., and Chen, L. (2013). Chronic inactivation of a neural circuit enhances LTP by inducing silent synapse formation. J. Neurosci. 33, 2087-2096. doi: 10.1523/JNEUROSCI.3880-12.2013

Bahari-Javan, S., Maddalena, A., Kerimoglu, C., Wittnam, J., Held, T., Bähr, M., et al. (2012). HDAC1 regulates fear extinction in mice. J. Neurosci. 32, 5062-5073. doi: 10.1523/JNEUROSCI.0079-12.2012

Ballarini, F., Moncada, D., Martinez, M. C., Alen, N., and Viola, H. (2009) Behavioral tagging is a general mechanism of long-term memory formation. Proc. Natl. Acad. Sci. U.S.A. 106, 14599-14604. doi: 10.1073/pnas.09070 78106

Barco, A., Patterson, S. L., Alarcón, J. M., Gromova, P., Mata-Roig, M., Morozov, A., et al. (2005). Gene expression profiling of facilitated L-LTP in VP16-CREB mice reveals that BDNF is critical for the maintenance of LTP and its synaptic capture. Neuron 48, 123-137. doi: 10.1016/j.neuron.2005.09.005

Baroncelli, L., Scali, M., Sansevero, G., Olimpico, F., Manno, I., Costa, M., et al. (2016). Experience affects critical period plasticity in the visual cortex through an epigenetic regulation of histone post-translational modifications. J. Neurosci. 36, 3430-3440. doi: 10.1523/JNEUROSCI.1787-15.2016

Bear, M. F. (1997). How do memories leave their mark? Nature 385, 481-482. doi: $10.1038 / 385481 \mathrm{a} 0$

Beck, H., and Yaari, Y. (2008). Plasticity of intrinsic neuronal properties in CNS disorders. Nat. Rev. Neurosci. 9, 357-369. doi: 10.1038/nrn2371

Beilharz, E. J., Zhukovsky, E., Lanahan, A. A., Worley, P. F., Nikolich, K., and Goodman, L. J. (1998). Neuronal activity induction of the stathmin-like gene RB3 in the rat hippocampus: possible role in neuronal plasticity. J. Neurosci. 18, 9780-9789. doi: 10.1523/JNEUROSCI.18-23-09780.1998

Bekinschtein, P., Cammarota, M., Igaz, L. M., Bevilaqua, L. R. M., Izquierdo, I., and Medina, J. H. (2007). Persistence of long-term memory storage requires a late protein synthesis- and BDNF- dependent phase in the hippocampus. Neuron 53, 261-277. doi: 10.1016/j.neuron.2006.11.025 
Bekinschtein, P., Cammarota, M., Katche, C., Slipczuk, L., Rossato, J. I., Goldin, A., et al. (2008). BDNF is essential to promote persistence of long-term memory storage. Proc. Natl. Acad. Sci. U.S.A. 105, 2711-2716. doi: 10.1073/pnas. 0711863105

Bekinschtein, P., Katche, C., Slipczuk, L., Gonzalez, C., Dorman, G., Cammarota, M., et al. (2010). Persistence of long-term memory storage: new insights into its molecular signatures in the hippocampus and related structures. Neurotox. Res. 18, 377-385. doi: 10.1007/s12640-010-91 55-5

Benito, E., and Barco, A. (2010). CREB's control of intrinsic and synaptic plasticity: implications for CREB-dependent memory models. Trends Neurosci. 33, 230-240. doi: 10.1016/j.tins.2010.02.001

Benito, E., and Barco, A. (2015). The neuronal activity-driven transcriptome. Mol. Neurobiol. 51, 1071-1088. doi: 10.1007/s12035-014-8772-z

Benito, E., Valor, L. M., Jimenez-Minchan, M., Huber, W., and Barco, A. (2011). cAMP response element-binding protein is a primary hub of activitydriven neuronal gene expression. J. Neurosci. 31, 18237-18250. doi: 10.1523/ JNEUROSCI.4554-11.2011

Benke, T. A., Luthi, A., Isaac, J. T., and Collingridge, G. L. (1998). Modulation of AMPA receptor unitary conductance by synaptic activity. Nature 393, 793-797. doi: $10.1038 / 31709$

Bito, H., Deisseroth, K., and Tsien, R. W. (1996). CREB phosphorylation and dephosphorylation: a $\mathrm{Ca}(2+)$ - and stimulus duration-dependent switch for hippocampal gene expression. Cell 87, 1203-1214. doi: 10.1016/S0092-8674(00) 81816-4

Bliss, T. V., and Collingridge, G. L. (1993). A synaptic model of memory: longterm potentiation in the hippocampus. Nature 361, 31-39. doi: 10.1038/361 $031 \mathrm{a} 0$

Bliss, T. V., and Gardner Medwin, A. R. (1973). Long lasting potentiation of synaptic transmission in the dentate area of the unanaesthetized rabbit following stimulation of the perforant path. J. Physiol. 232, 357-374. doi: 10. 1113/jphysiol.1973.sp010274

Bliss, T. V., and Lømo, T. (1973). Long lasting potentiation of synaptic transmission in the dentate area of the anaesthetized rabbit following stimulation of the perforant path. J. Physiol. 232, 331-356. doi: 10.1113/jphysiol.1973.sp010273

Bourne, J., and Harris, K. M. (2007). Do thin spines learn to be mushroom spines that remember? Curr. Opin. Neurobiol. 17, 381-386. doi: 10.1016/j.conb.2007. 04.009

Bourtchuladze, R., Frenguelli, B., Blendy, J., Cioffi, D., Schutz, G., and Silva, A. J. (1994). Deficient long-term memory in mice with a targeted mutation of the cAMP-responsive element-binding protein. Cell 79, 59-68. doi: 10.1016/00928674(94)90400-6

Bousiges, O., Vasconcelos, A. P., de Neidl, R., Cosquer, B., Herbeaux, K., Panteleeva, I., et al. (2010). Spatial memory consolidation is associated with induction of several lysine-acetyltransferase (histone acetyltransferase) expression levels and $\mathrm{H} 2 \mathrm{~B} / \mathrm{H} 4$ acetylation-dependent transcriptional events in the rat hippocampus. Neuropsychopharmacology 35, 2521-2537. doi: 10.1038/ npp. 2010.117

Brakeman, P. R., Lanahan, A. A., O’Brien, R., Roche, K., Barnes, C. A., Huganir, R. L., et al. (1997). Homer: a protein that selectively binds metabotropic glutamate receptors. Nature 386, 284-288. doi: 10.1038/3862 $84 \mathrm{a} 0$

Butler, M. P., O'Connor, J. J., and Moynagh, P. N. (2004). Dissection of tumornecrosis factor-alpha inhibition of long-term potentiation (LTP) reveals a p38 mitogen-activated protein kinase-dependent mechanism which maps to earlybut not late-phase LTP. Neuroscience 124, 319-326. doi: 10.1016/j.neuroscience. 2003.11.040

Cai, D. J., Aharoni, D., Shuman, T., Shobe, J., Biane, J., Song, W., et al. (2016). A shared neural ensemble links distinct contextual memories encoded close in time. Nature 534, 115-118. doi: 10.1038/nature17955

Caroni, P., Chowdhury, A., and Lahr, M. (2014). Synapse rearrangements upon learning: from divergent-sparse connectivity to dedicated sub-circuits. Trends Neurosci. 37, 604-614. doi: 10.1016/j.tins.2014.08.011

Cassini, L. F., Sierra, R. O., Haubrich, J., Crestani, A. P., Santana, F., de Oliveira Alvares, L., et al. (2013). Memory reconsolidation allows the consolidation of a concomitant weak learning through a synaptic tagging and capture mechanism. Hippocampus 23, 931-941. doi: 10.1002/hipo.2 2149
Cho, M. H., Cao, X., Wang, D., and Tsien, J. Z. (2007). Dentate gyrus-specific manipulation of beta-Ca2+/calmodulin-dependent kinase II disrupts memory consolidation. Proc. Natl. Acad. Sci. U. S. A. 104, 16317-16322. doi: 10.1073/ pnas.0703344104

Choi, J.-H., Sim, S.-E., Kim, J., Choi, D. Il, Oh, J., Ye, S., et al. (2018). Interregional synaptic maps among engram cells underlie memory formation. Science 360, 430-435. doi: 10.1126/science.aas9204

Chowdhury, S., Shepherd, J. D., Okuno, H., Lyford, G., Petralia, R. S., Plath, N., et al. (2006). Arc interacts with the endocytic machinery to regulate ampa receptor trafficking. Neuron 52, 445-459. doi: 10.1016/j.neuron.2006.0 8.033

Chwang, W. B., Arthur, J. S., Schumacher, A., and Sweatt, J. D. (2007). The nuclear kinase mitogen- and stress-activated protein kinase 1 regulates hippocampal chromatin remodeling in memory formation. J. Neurosci. 27, 12732-12742. doi: 10.1523/JNEUROSCI.2522-07.2007

Citri, A., and Malenka, R. C. (2008). Synaptic plasticity: multiple forms, functions, and mechanisms. Neuropsychopharmacology 33, 18-41. doi: 10.1038/sj.npp. 1301559

Cole, A. J., Saffen, D. W., Baraban, J. M., and Worley, P. F. (1989). Rapid increase of an immediate early gene messenger RNA in hippocampal neurons by synaptic NMDA receptor activation. Nature 340, 474-476. doi: 10.1038/340474a0

Dash, P. K., Orsi, S. A., and Moore, A. N. (2005). Sequestration of serum response factor in the hippocampus impairs long-term spatial memory. J. Neurochem. 93, 269-278. doi: 10.1111/j.1471-4159.2004.03016.x

Davis, S., Vanhoutte, P., Pagès, C., Caboche, J., and Laroche, S. (2000). The MAPK/ERK cascade targets both Elk-1 and cAMP response element- binding protein to control long-term potentiation-dependent gene expression in the dentate gyrus in vivo. J. Neurosci. 20, 4563-4572. doi: 10.1523/JNEUROSCI. 20-12-04563.2000

Deisseroth, K., Bito, H., and Tsien, R. W. (1996). Signaling from synapse to nucleus: postsynaptic CREB phosphorylation during multiple forms of hippocampal synaptic plasticity. Neuron 16, 89-101. doi: 10.1016/S0896-6273(00) 80026-4

Dolphin, A. C., Errington, M. L., and Bliss, T. V. P. (1982). Long-term potentiation of the perforant path in vivo is associated with increased glutamate release. Nature 297, 496-497. doi: 10.1038/297496a0

Douglas, R. M., and Goddard, G. V. (1975). Long-term potentiation of the perforant path-granule cell synapse in the rat hippocampus. Brain Res. 86, 205-215. doi: 10.1016/0006-8993(75)90697-6

Dragunow, M., Abraham, W. C., Goulding, M., Mason, S. E., Robertson, H. A., and Faull, R. L. (1989). Long-term potentiation and the induction of c-fos mRNA and proteins in the dentate gyrus of unanesthetized rats. Neurosci. Lett. 101, 274-280. doi: 10.1016/0304-3940(89)90545-4

Dudai, Y. (1996). Consolidation: fragility on the road to the engram. Neuron 17, 367-370. doi: 10.1016/S0896-6273(00)80168-3

Dudai, Y., and Eisenberg, M. (2004). Rites of passage of the engram: reconsolidation and the lingering consolidation hypothesis. Neuron 44, 93-100. doi: 10.1016/j.neuron.2004.09.003

Dudek, S. M., and Fields, R. D. (2002). Somatic action potentials are sufficient for late-phase LTP-related cell signaling. Proc. Natl. Acad. Sci. U.S.A. 99, 3962-3967. doi: 10.1073/pnas.062510599

Dunsmoor, J. E., Murty, V. P., Davachi, L., and Phelps, E. A. (2015). Emotional learning selectively and retroactively strengthens memories for related events. Nature 520, 345-348. doi: 10.1038/nature14106

Eichenbaum, H. (2016). Still searching for the engram. Learn. Behav. 44, 209-222. doi: 10.3758/s13420-016-0218-1

Fischer, A., Sananbenesi, F., Wang, X., Dobbin, M., and Tsai, L. H. (2007). Recovery of learning and memory is associated with chromatin remodelling. Nature 447, 178-182. doi: 10.1038/nature05772

Frankland, P. W., and Bontempi, B. (2005). The organization of recent and remote memories. Nat. Rev. Neurosci. 6, 119-130. doi: 10.1038/nrn1607

Freudenthal, R., Boccia, M. M., Acosta, G. B., Blake, M. G., Merlo, E., Baratti, C. M., et al. (2005). NF- $\kappa B$ transcription factor is required for inhibitory avoidance long-term memory in mice. Eur. J. Neurosci. 21, 2845-2852. doi: 10.1111/j. 1460-9568.2005.04126.x

Freudenthal, R., Romano, A., and Routtenberg, A. (2004). Transcription factor NF- $\mathrm{BB}$ activation after in vivo perforant path LTP in mouse hippocampus. Hippocampus 14, 677-683. doi: 10.1002/hipo.20020 
Frey, S., Bergado-Rosado, J., Seidenbecher, T., Pape, H. C., and Frey, J. U. (2001). Reinforcement of early long-term potentiation (early-LTP) in dentate gyrus by stimulation of the basolateral amygdala: heterosynaptic induction mechanisms of late-LTP. J. Neurosci. 21, 3697-3703. doi: 10.1523/JNEUROSCI.21-10-03697. 2001

Frey, S., and Frey, J. U. (2008). "Synaptic tagging” and "cross-tagging” and related associative reinforcement processes of functional plasticity as the cellular basis for memory formation. Prog. Brain Res. 169, 117-143. doi: 10.1016/S00796123(07)00007-6

Frey, U., Huang, Y. Y., and Kandel, E. R. (1993). Effects of cAMP simulate a late stage of LTP in hippocampal CA1 neurons. Science 260, 1661-1664. doi: $10.1126 /$ science. 8389057

Frey, U., and Morris, R. G. M. (1997). Synaptic tagging and long-term potentiation. Nature 385, 533-536. doi: 10.1038/385533a0

Fujii, S., Kato, H., and Kuroda, Y. (2002). Cooperativity between extracellular adenosine $5^{\prime}$-triphosphate and activation of N-methyl-D-aspartate receptors in long-term potentiation induction in hippocampal CA1 neurons. Neuroscience 113, 617-628. doi: 10.1016/S0306-4522(02)00190-2

Fujita, Y., Morinobu, S., Takei, S., Fuchikami, M., Matsumoto, T., Yamamoto, S., et al. (2012). Vorinostat, a histone deacetylase inhibitor, facilitates fear extinction and enhances expression of the hippocampal NR2B-containing NMDA receptor gene. J. Psychiatr. Res. 46, 635-643. doi: 10.1016/j.jpsychires. 2012.01.026

Fukuchi, M., Nakashima, F., Tabuchi, A., Shimotori, M., Tatsumi, S., Okuno, H., et al. (2015). Class I histone deacetylase-mediated repression of the proximal promoter of the activity-regulated cytoskeleton-associated protein gene regulates its response to brain-derived neurotrophic factor. J. Biol. Chem. 290, 6825-6836. doi: 10.1074/jbc.M114.617258

Gisabella, B., Rowan, M. J., and Anwyl, R. (2003). Mechanisms underlying the inhibition of long-term potentiation by preconditioning stimulation in the hippocampus in vitro. Neuroscience 121, 297-305. doi: 10.1016/S0306-4522(03) 00440-8

Goelet, P., Castellucci, V. F., Schacher, S., and Kandel, E. R. (1986). The long and the short of long-term memory-a molecular framework. Nature 322, 419-422. doi: 10.1038/322419a0

Gräff, J., Joseph, N. F., Horn, M. E., Samiei, A., Meng, J., Seo, J., et al. (2014). Epigenetic priming of memory updating during reconsolidation to attenuate remote fear memories. Cell 156, 261-276. doi: 10.1016/j.cell.2013.12.020

Gräff, J., Kim, D., Dobbin, M. M., and Li-Huei, T. (2011). Epigenetic regulation of gene expression in physiological and pathological brain processes. Physiol. Rev. 91, 603-649. doi: 10.1152/physrev.00012.2010

Gräff, J., Rei, D., Guan, J. S., Wang, W. Y., Seo, J., Hennig, K. M., et al. (2012). An epigenetic blockade of cognitive functions in the neurodegenerating brain. Nature 483, 222-226. doi: 10.1038/nature10849

Gräff, J., and Tsai, L. H. (2013). Histone acetylation: molecular mnemonics on the chromatin. Nat. Rev. Neurosci. 14, 97-111. doi: 10.1038/nrn3427

Guan, J. S., Haggarty, S. J., Giacometti, E., Dannenberg, J. H., Joseph, N., Gao, J., et al. (2009). HDAC2 negatively regulates memory formation and synaptic plasticity. Nature 459, 55-60. doi: 10.1038/nature07925

Guzowski, J. F., Lyford, G. L., Stevenson, G. D., Houston, F. P., McGaugh, J. L., Worley, P. F., et al. (2000). Inhibition of activity-dependent arc protein expression in the rat hippocampus impairs the maintenance of long-term potentiation and the consolidation of long-term memory. J. Neurosci. 20, 3993-4001. doi: 10.1523/JNEUROSCI.20-11-03993.2000

Guzowski, J. F., and McGaugh, J. L. (1997). Antisense oligodeoxynucleotidemediated disruption of hippocampal cAMP response element binding protein levels impairs consolidation of memory for water maze training. Proc. Natl. Acad. Sci. U.S.A. 94, 2693-2698. doi: 10.1073/pnas.94.6.2693

Han, J. H., Kushner, S. A., Yiu, A. P., Cole, C. J., Matynia, A., Brown, R. A., et al. (2007). Neuronal competition and selection during memory formation. Science 316, 457-460. doi: 10.1126/science.1139438

Harrow, J., Frankish, A., Gonzalez, J. M., Tapanari, E., Diekhans, M., Kokocinski, F., et al. (2012). GENCODE: the reference human genome annotation for The ENCODE Project. Genome Res. 22, 1760-1774. doi: 10.1101/ gr.135350.111

Harward, S. C., Hedrick, N. G., Hall, C. E., Parra-Bueno, P., Milner, T. A., Pan, E., et al. (2016). Autocrine BDNF-TrkB signalling within a single dendritic spine. Nature 28, 99-103. doi: 10.1038/nature 19766
Hausser, M., Spruston, N., and Stuart, G. J. (2000). Diversity and dynamics of dendritic signaling. Science 290, 739-744. doi: 10.1126/science.290.5492.739

Hayashi-Takagi, A., Yagishita, S., Nakamura, M., Shirai, F., Wu, Y. I., Loshbaugh, A. L., et al. (2015). Labelling and optical erasure of synaptic memory traces in the motor cortex. Nature 525, 333-338. doi: 10.1038/nature1 5257

Hebb, D. O. (1949). The Organisation of Behaviour: A Neuropsychological Theory. New York: Wiley.

Hubener, M., and Bonhoeffer, T. (2014). Neuronal plasticity: beyond the critical period. Cell 159, 727-737. doi: 10.1016/j.cell.2014.10.035

Hulme, S. R., Jones, O. D., Ireland, D. R., and Abraham, W. C. (2012). Calciumdependent but action potential-independent BCM-like metaplasticity in the Hippocampus. J. Neurosci. 32, 6785-6794. doi: 10.1523/JNEUROSCI.0634-12. 2012

Impey, S., Smith, D. M., Obrietan, K., Donahue, R., Wade, C., and Storm, D. R. (1998). Stimulation of cAMP response element (CRE)-mediated transcription during contextual learning. Nat. Neurosci. 1, 595-601. doi: 10.1038/2830

Izumi, Y., Tokuda, K., and Zorumski, C. F. (2008). Long-term potentiation inhibition by low-level N-methyl-D-aspartate receptor activation involves calcineurin, nitric oxide, and p38 mitogen-activated protein kinase. Hippocampus 18, 258-265. doi: 10.1002/hipo.20383

Jancic, D., Lopez de Armentia, M., Valor, L. M., Olivares, R., and Barco, A. (2009). Inhibition of cAMP response element-binding protein reduces neuronal excitability and plasticity, and triggers neurodegeneration. Cereb. Cortex 19, 2535-2547. doi: 10.1093/cercor/bhp004

Jenks, K. R., Kim, T., Pastuzyn, E. D., Okuno, H., Taibi, A. V., Bito, H., et al. (2017). Arc restores juvenile plasticity in adult mouse visual cortex. Proc. Natl. Acad. Sci. U.S.A. 114, 9182-9187. doi: 10.1073/pnas.1700866114

Jones, M. W., Errington, M. L., French, P. J., Fine, A., Bliss, T. V., Garel, S., et al. (2001). A requirement for the immediate early gene Zif268 in the expression of late LTP and long-term memories. Nat. Neurosci. 4, 289-296. doi: 10.1038/ 85138

Josselyn, S. A., Kohler, S., and Frankland, P. W. (2015). Finding the engram. Nat. Rev. Neurosci. 16, 521-534. doi: 10.1038/nrn4000

Kang, H. J., and Schuman, E. M. (1995). Neurotrophin-induced modulation of synaptic transmission in the adult hippocampus. J. Physiol. 89, 11-22.

Kastellakis, G., Cai, D. J., Mednick, S. C., Silva, A. J., and Poirazi, P. (2015). Synaptic clustering within dendrites: an emerging theory of memory formation. Prog. Neurobiol. 126, 19-35. doi: 10.1016/j.pneurobio.2014.12.002

Katche, C., Bekinschteina, P., Slipczuk, L., Goldin, A., Izquierdo, I. A., Cammarota, M., et al. (2010). Delayed wave of c-Fos expression in the dorsal hippocampus involved specifically in persistence of long-term memory storage. Proc. Natl. Acad. Sci. U.S.A. 107, 349-354. doi: 10.1073/pnas.0912931107

Katche, C., Goldin, A., Gonzalez, C., Bekinschtein, P., and Medina, J. H. (2012). Maintenance of long-term memory storage is dependent on late posttraining Egr-1 expression. Neurobiol. Learn. Mem. 98, 220-227. doi: 10.1016/j.nlm.2012. 08.001

Kato, A., Ozawa, F., Saitoh, Y., Fukazawa, Y., Sugiyama, H., and Inokuchi, K. (1998). Novel members of the Vesl/Homer family of PDZ proteins that bind metabotropic glutamate receptors. J. Biol. Chem. 273, 23969-23975. doi: 10. 1074/jbc.273.37.23969

Kato, A., Ozawa, F., Saitoh, Y., Hirai, K., and Inokuchi, K. (1997). vesl, a gene encoding VASP/Ena family related protein, is upregulated during seizure, longterm potentiation and synaptogenesis. FEBS Lett. 412, 183-189. doi: 10.1016/ S0014-5793(97)00775-8

Kelleher, R. J. III, Govindarajan, A., and Tonegawa, S. (2004). Translational regulatory mechanisms in persistent forms of synaptic plasticity. Neuron 44, 59-73. doi: 10.1016/j.neuron.2004.09.013

Kelly, R. D. W., and Cowley, S. M. (2013). The physiological roles of histone deacetylase (HDAC) 1 and 2: complex co-stars with multiple leading parts. Biochem. Soc. Trans. 41, 741-749. doi: 10.1042/BST20130010

Khalaf, O., Resch, S., Dixsaut, L., Gorden, V., Glauser, L., and Graff, J. (2018). Reactivation of recall-induced neurons contributes to remote fear memory attenuation. Science 360, 1239-1242. doi: 10.1126/science.aas 9875

Kim, D., Frank, C. L., Dobbin, M. M., Tsunemoto, R. K., Tu, W., Peng, P. L., et al. (2008). Deregulation of HDAC1 by p25/Cdk5 in neurotoxicity. Neuron 60, 803-817. doi: 10.1016/j.neuron.2008.10.015 
Korte, M., Kang, H., Bonhoeffer, T., and Schuman, E. (1998). A role for BDNF in the late-phase of hippocampal long-term potentiation. Neuropharmacology 37, 553-559. doi: 10.1016/S0028-3908(98)00035-5

Korzus, E., Rosenfeld, M. G., and Mayford, M. (2004). CBP histone acetyltransferase activity is a critical component of memory consolidation. Neuron 42, 961-972. doi: 10.1016/j.neuron.2004.06.002

Larkum, M. E., and Nevian, T. (2008). Synaptic clustering by dendritic signalling mechanisms. Curr. Opin. Neurobiol. 18, 321-331. doi: 10.1016/j.conb.2008. 08.013

Lennartsson, A., Arner, E., Fagiolini, M., Saxena, A., Andersson, R., Takahashi, H., et al. (2015). Remodeling of retrotransposon elements during epigenetic induction of adult visual cortical plasticity by HDAC inhibitors. Epigenetics Chromatin 8:55. doi: 10.1186/s13072-015-0043-3

Lesburguères, E., Gobbo, O. L., Alaux-Cantin, S., Hambucken, A., Trifilieff, P., and Bontempi, B. (2011). Early tagging of cortical networks is required for the formation of enduring associative memory. Science 331, 924-928. doi: 10.1126/ science. 1196164

Levenson, J. M., Choi, S., Lee, S.-Y., Cao, Y. A., Ahn, H. J., Worley, K. C., et al. (2004a). A bioinformatics analysis of memory consolidation reveals involvement of the transcription factor c-Rel. J. Neurosci. 24, 3933-3943.

Levenson, J. M., O’Riordan, K. J., Brown, K. D., Trinh, M. A., Molfese, D. L., and Sweatt, J. D. (2004b). Regulation of histone acetylation during memory formation in the hippocampus. J. Biol. Chem. 279, 40545-40559.

Link, W., Konietzko, U., Kauselmann, G., Krug, M., Schwanke, B., Frey, U., et al. (1995). Somatodendritic expression of an immediate early gene is regulated by synaptic activity. Proc. Natl. Acad. Sci. U.S.A. 92, 5734-5738. doi: 10.1073/pnas. 92.12.5734

Lisman, J., Cooper, K., Sehgal, M., and Silva, A. J. (2018). Memory formation depends on both synapse-specific modifications of synaptic strength and cellspecific increases in excitability. Nat. Neurosci. 21, 309-314. doi: 10.1038/ s41593-018-0076-6

Liu, X., Ramirez, S., Pang, P. T., Puryear, C. B., Govindarajan, A., Deisseroth, K., et al. (2012). Optogenetic stimulation of a hippocampal engram activates fear memory recall. Nature 484, 381-385. doi: 10.1038/nature11028

Lopez de Armentia, M., Jancic, D., Olivares, R., Alarcón, J. M., Kandel, E. R., and Barco, A. (2007). cAMP response element-binding protein-mediated gene expression increases the intrinsic excitability of CA1 pyramidal neurons. J. Neurosci. 27, 13909-13918. doi: 10.1523/JNEUROSCI.3850-07.2007

Lopez-Atalaya, J. P., Ito, S., Valor, L. M., Benito, E., and Barco, A. (2013). Genomic targets, and histone acetylation and gene expression profiling of neural HDAC inhibition. Nucleic Acids Res. 41, 8072-8084. doi: 10.1093/nar/gkt590

Lu, W., Man, H., Ju, W., Trimble, W. S., MacDonald, J. F., and Wang, Y. T. (2001). Activation of synaptic NMDA receptors induces membrane insertion of new AMPA receptors and LTP in cultured hippocampal neurons. Neuron 29, 243-254. doi: 10.1016/S0896-6273(01)00194-5

Lubin, F. D., and Sweatt, J. D. (2007). The IkappaB kinase regulates chromatin structure during reconsolidation of conditioned fear memories. Neuron 55, 942-957. doi: 10.1016/j.neuron.2007.07.039

Lyford, G. L., Yamagata, K., Kaufmann, W. E., Barnes, C. A., Sanders, L. K., Copeland, N. G., et al. (1995). Arc, a growth factor and activity-regulated gene, encodes a novel cytoskeleton-associated protein that is enriched in neuronal dendrites. Neuron 14, 433-445. doi: 10.1016/0896-6273(95)90299-6

Lynch, G. S., Dunwiddie, T., and Gribkoff, V. (1977). Heterosynaptic depression: a postsynaptic correlate of long-term potentiation. Nature 266, 737-739. doi: $10.1038 / 266737 \mathrm{a} 0$

Maag, J. L. V., Kaczorowski, D. C., Panja, D., Peters, T. J., Bramham, C. R., Wibrand, K., et al. (2017). Widespread promoter methylation of synaptic plasticity genes in long-term potentiation in the adult brain in vivo. $B M C$ Genomics 18:250. doi: 10.1186/s12864-017-3621-x

Mahgoub, M., and Monteggia, L. M. (2014). A role for histone deacetylases in the cellular and behavioral mechanisms underlying learning and memory. Learn. Mem. 21, 564-568. doi: 10.1101/lm.036012.114

Matsuzaki, M., Honkura, N., Ellis-Davies, G. C., and Kasai, H. (2004). Structural basis of long-term potentiation in single dendritic spines. Nature 429, 761-766. doi: $10.1038 /$ nature 02617

McKay, B. M., Matthews, E. A., Oliveira, F. A., and Disterhoft, J. F. (2009). Intrinsic neuronal excitability is reversibly altered by a single experience in fear conditioning. J. Neurophysiol. 102, 2763-2770. doi: 10.1152/jn.00347.2009
Medina, J. H., Bekinschtein, P., Cammarota, M., and Izquierdo, I. (2008). Do memories consolidate to persist or do they persist to consolidate? Behav. Brain Res. 192, 61-69. doi: 10.1016/j.bbr.2008.02.006

Messaoudi, E., Kanhema, T., Soulé, J., Tiron, A., Dagyte, G., Da Silva, B., et al. (2007). Sustained Arc/Arg3.1 synthesis controls long-term potentiation consolidation through regulation of local actin polymerization in the dentate gyrus in vivo. J. Neurosci. 27, 10445-10455. doi: 10.1523/JNEUROSCI.2883-07. 2007

Miller, C. A., Campbell, S. L., and Sweatt, J. D. (2008). DNA methylation and histone acetylation work in concert to regulate memory formation and synaptic plasticity. Neurobiol. Learn. Mem. 89, 599-603. doi: 10.1016/j.nlm.2007.07.016

Miller, C. A., Gavin, C. F., White, J. A., Parrish, R. R., Honasoge, A., Yancey, C. R., et al. (2010). Cortical DNA methylation maintains remote memory. Nat. Neurosci. 13, 664-666. doi: 10.1038/nn.2560

Minatohara, K., Akiyoshi, M., and Okuno, H. (2015). Role of immediate-early genes in synaptic plasticity and neuronal ensembles underlying the memory trace. Front. Mol. Neurosci. 8:78. doi: 10.3389/fnmol.2015.00078

Morris, M. J., Mahgoub, M., Na, E. S., Pranav, H., and Monteggia, L. M. (2013). Loss of histone deacetylase 2 improves working memory and accelerates extinction learning. J. Neurosci. 33, 6401-6411. doi: 10.1523/JNEUROSCI.1001-12.2013

Moyer, J. R. Jr., Thompson, L. T., and Disterhoft, J. F. (1996). Trace eyeblink conditioning increases CA1 excitability in a transient and learning-specific manner. J. Neurosci. 16, 5536-5546. doi: 10.1523/JNEUROSCI.16-17-05536. 1996

Mozzachiodi, R., and Byrne, J. H. (2010). More than synaptic plasticity: role of nonsynaptic plasticity in learning and memory. Trends Neurosci. 33, 17-26. doi: 10.1016/j.tins.2009.10.001

Nabavi, S., Fox, R., Proulx, C. D., Lin, J. Y., Tsien, R. Y., and Malinow, R. (2014). Engineering a memory with LTD and LTP. Nature 511, 348-352. doi: 10.1038/ nature13294

Nader, K., and Hardt, O. (2009). A single standard for memory: the case for reconsolidation. Nat. Rev. Neurosci. 10, 224-234. doi: 10.1038/nrn2590

Nader, K., Schafe, G. E., and Le Doux, J. E. (2000). Fear memories require protein synthesis in the amygdala for reconsolidation after retrieval. Nature 406, 722-726. doi: 10.1038/35021052

Nakayama, D., Iwata, H., Teshirogi, C., Ikegaya, Y., Matsuki, N., and Nomura, H. (2015). Long-delayed expression of the immediate early gene Arc/Arg3.1 refines neuronal circuits to perpetuate fear memory. J. Neurosci. 35, 819-830. doi: 10.1523/JNEUROSCI.2525-14.2015

Neves, G., Cooke, S. F., and Bliss, T. V. P. (2008). Synaptic plasticity, memory and the hippocampus: a neural network approach to causality. Nat. Rev. Neurosci.9, 65-75. doi: 10.1038/nrn2303

Nguyen, P. V., Abel, T., and Kandel, E. R. (1994). Requirement of a critical period of transcription for induction of a late phase of LTP. Science 265, 1104-1107. doi: 10.1126/science. 8066450

Nido, G. S., Ryan, M. M., Benuskova, L., and Williams, J. M. (2015). Dynamical properties of gene regulatory networks involved in longterm potentiation. Front. Mol. Neurosci. 8:42. doi: 10.3389/fnmol.2015. 00042

Nido, G. S., Williams, J. M., and Benuskova, L. (2012). "Bistable properties of a memory-related gene regulatory network," in Proceedings of the International Joint Conference on Neural Networks International Neural Network Society (Brisbane, QLD: IEEE). doi: 10.1109/IJCNN.2012.6252588

Nomoto, M., Ohkawa, N., Nishizono, H., Yokose, J., Suzuki, A., Matsuo, M., et al. (2016). Cellular tagging as a neural network mechanism for behavioural tagging. Nat. Commun. 7:12319. doi: 10.1038/ncomms12319

Okuno, H., Akashi, K., Ishii, Y., Yagishita-Kyo, N., Suzuki, K., Nonaka, M., et al. (2012). Inverse synaptic tagging of inactive synapses via dynamic interaction of Arc/Arg3.1 with CaMKIIbeta. Cell 149, 886-898. doi: 10.1016/j.cell.2012.0 2.062

Oliveira, A. M. M. (2016). DNA methylation: a permissive mark in memory formation and maintenance. Learn. Mem. 23, 587-593. doi: 10.1101/lm. 042739.116

Otmakhov, N., Khibnik, L., Otmakhova, N., Carpenter, S., Riahi, S., Asrican, B., et al. (2004). Forskolin-induced LTP in the CA1 hippocampal region is NMDA receptor dependent. J. Neurophysiol. 91, 1955-1962. doi: 10.1152/jn.00941.2003

Pastuzyn, E. D., Day, C. E., Kearns, R. B., Kyrke-Smith, M., Taibi, A. V., McCormick, J., et al. (2018). The neuronal gene arc encodes a repurposed 
retrotransposon gag protein that mediates intercellular RNA transfer. Cell 172, 275.e18-288.e18. doi: 10.1016/j.cell.2017.12.024

Peleg, S., Sananbenesi, F., Zovoilis, A., Burkhardt, S., Bahari-Javan, S., Agis-Balboa, R. C., et al. (2010). Altered histone acetylation is associated with age-dependent memory impairment in mice. Science 328, 753-756. doi: 10.1126/science. 1186088

Penney, J., and Tsai, L.-H. (2014). Histone deacetylases in memory and cognition. Sci. Signal. 7:re12. doi: 10.1126/scisignal.aaa0069

Plath, N., Ohana, O., Dammermann, B., Errington, M. L., Schmitz, D., Gross, C., et al. (2006). Arc/Arg3.1 is essential for the consolidation of synaptic plasticity and memories. Neuron 52, 437-444. doi: 10.1016/j.neuron.2006.0 8.024

Poo, M.-M., Pignatelli, M., Ryan, T. J., Tonegawa, S., Bonhoeffer, T., Martin, K. C., et al. (2016). What is memory? The present state of the engram. BMC Biol. 14:40. doi: 10.1186/s12915-016-0261-6

Przybyslawski, J., and Sara, S. J. (1997). Reconsolidation of memory after its reactivation. Behav. Brain Res. 84, 241-246. doi: 10.1016/S0166-4328(96)00 $153-2$

Putignano, E., Lonetti, G., Cancedda, L., Ratto, G., Costa, M., Maffei, L., et al. (2007). Developmental downregulation of histone posttranslational modifications regulates visual cortical plasticity. Neuron 53, 747-759. doi: 10 . 1016/j.neuron.2007.02.007

Ramirez, S., Liu, X., Lin, P. A., Suh, J., Pignatelli, M., Redondo, R. L., et al. (2013). Creating a false memory in the hippocampus. Science 341, 387-391. doi: 10.1126/science.1239073

Ramirez, S., Liu, X., MacDonald, C. J., Moffa, A., Zhou, J., Redondo, R. L., et al. (2015). Activating positive memory engrams suppresses depression-like behaviour. Nature 522, 335-339. doi: 10.1038/nature14514

Raymond, C. R., and Redman, S. J. (2006). Spatial segregation of neuronal calcium signals encodes different forms of LTP in rat hippocampus. J. Physiol. 570, 97-111. doi: 10.1113/jphysiol.2005.098947

Raymond, C. R., Thompson, V. L., Tate, W. P., and Abraham, W. C. (2000). Metabotropic glutamate receptors trigger homosynaptic protein synthesis to prolong long-term potentiation. J. Neurosci. 20, 969-976. doi: 10.1523/ JNEUROSCI.20-03-00969.2000

Redondo, R. L., and Morris, R. G. M. (2011). Making memories last: the synaptic tagging and capture hypothesis. Nat. Rev. Neurosci. 12, 17-30. doi: 10.1038/ nrn2963

Reymann, K. G., Matthies, H. K., Frey, U., Vorobyev, V. S., and Matthies, H. (1986). Calcium-induced long-term potentiation in the hippocampal slice: characterization of the time course and conditions. Brain Res. Bull. 17, 291-296. doi: 10.1016/0361-9230(86)90234-0

Rioult-Pedotti, M. S., Donoghue, J. P., and Dunaevsky, A. (2007). Plasticity of the synaptic modification range. J. Neurophysiol. 98, 3688-3695. doi: 10.1152/jn. 00164.2007

Roy, D. S., Arons, A., Mitchell, T. I., Pignatelli, M., Ryan, T. J., and Tonegawa, S. (2016). Memory retrieval by activating engram cells in mouse models of early Alzheimer's disease. Nature 531, 508-512. doi: 10.1038/nature1 7172

Ryan, M. M., Mason-Parker, S. E., Tate, W. P., Abraham, W. C., and Williams, J. M. (2011). Rapidly induced gene networks following induction of long-term potentiation at perforant path synapses in vivo. Hippocampus 21, 541-553. doi: 10.1002/hipo. 20770

Ryan, M. M., Ryan, B., Kyrke-Smith, M., Logan, B., Tate, W. P. P., Abraham, W. C. C., et al. (2012). Temporal profiling of gene networks associated with the late phase of long-term potentiation in vivo. PLOS One 7:e40538. doi: 10.1371/journal.pone.0040538

Sacktor, T. C., Osten, P., Valsamis, H., Jiang, X., Naik, M. U., and Sublette, E. (1993). Persistent activation of the $\zeta$ isoform of protein kinase $C$ in the maintenance of long-term potentiation. Proc. Natl. Acad. Sci. U.S.A. 90, 8342-8346. doi: 10.1073/pnas.90.18.8342

Sajikumar, S., and Frey, J. U. (2004). Late-associativity, synaptic tagging, and the role of dopamine during LTP and LTD. Neurobiol. Learn. Mem. 82, 12-25. doi: 10.1016/j.nlm.2004.03.003

Sajikumar, S., and Korte, M. (2011). Metaplasticity governs compartmentalization of synaptic tagging and capture through brain-derived neurotrophic factor (BDNF) and protein kinase Mzeta (PKMzeta). Proc. Natl. Acad. Sci. U.S.A. 108, 2551-2556. doi: 10.1073/pnas. 1016849108
Sajikumar, S., Navakkode, S., and Frey, J. U. (2007). Identification of compartmentand process-specific molecules required for "synaptic tagging" during longterm potentiation and long-term depression in hippocampal CA1. J. Neurosci. 27, 5068-5080. doi: 10.1523/JNEUROSCI.4940-06.2007

Sajikumar, S., Navakkode, S., Sacktor, T. C., and Frey, J. U. (2005). Synaptic tagging and cross-tagging: the role of protein kinase Mzeta in maintaining longterm potentiation but not long-term depression. J. Neurosci. 25, 5750-5756. doi: 10.1523/JNEUROSCI.1104-05.2005

Schwartzkroin, P. A., and Wester, K. (1975). Long-lasting facilitation of a synaptic potential following tetanization in the in vitro hippocampal slice. Brain Res. 89 , 107-119. doi: 10.1016/0006-8993(75)90138-9

Sheng, M., Thompson, M. A., and Greenberg, M. E. (1991). CREB: a Ca(2+)regulated transcription factor phosphorylated by calmodulin-dependent kinases. Science 252, 1427-1430. doi: 10.1126/science.1646483

Shepherd, J. D., and Bear, M. F. (2011). New views of Arc, a master regulator of synaptic plasticity. Nat. Neurosci. 14, 279-284. doi: 10.1038/nn.2708

Shirke, A. M., and Malinow, R. (1997). Mechanisms of potentiation by calcium-calmodulin kinase II of postsynaptic sensitivity in rat hippocampal CA1 neurons. J. Neurophysiol. 78, 2682-2692. doi: 10.1152/jn.1997.78.5. 2682

Stefanko, D. P., Barrett, R. M., Ly, A. R., Reolon, G. K., and Wood, M. A. (2009). Modulation of long-term memory for object recognition via HDAC inhibition. Proc. Natl. Acad. Sci. U.S.A. 106, 9447-9452. doi: 10.1073/pnas.0903964106

Steward, O., Farris, S., Pirbhoy, P. S., Darnell, J., and Driesche, S. J. (2014). Localization and local translation of Arc/Arg3.1 mRNA at synapses: some observations and paradoxes. Front. Mol. Neurosci. 7:101. doi: 10.3389/fnmol. 2014.00101

Steward, O., Wallace, C. S., Lyford, G. L., and Worley, P. F. (1998). Synaptic activation causes the mRNA for the IEG Arc to localize selectively near activated postsynaptic sites on dendrites. Neuron 21, 741-751. doi: 10.1016/S08966273(00)80591-7

Steward, O., and Worley, P. F. (2001). Selective targeting of newly synthesized Arc mRNA to active synapses requires NMDA receptor activation. Neuron 30, 227-240. doi: 10.1016/S0896-6273(01)00275-6

Stilling, R. M., and Fischer, A. (2011). The role of histone acetylation in ageassociated memory impairment and Alzheimer's disease. Neurobiol. Learn. Mem. 96, 19-26. doi: 10.1016/j.nlm.2011.04.002

Sweatt, J. D. (2016). Neural plasticity \& behavior - sixty years of conceptual advances. J. Neurochem. 139, 179-199. doi: 10.1111/jnc.13580

Takeuchi, T., Duszkiewicz, A. J., and Morris, R. G. M. (2013). The synaptic plasticity and memory hypothesis: encoding, storage and persistence. Philos. Trans. R. Soc. B Biol. Sci. 369:20130288. doi: 10.1098/rstb.2013.0288

Thibault, O., Joly, M., Muller, D., Schottler, F., Dudek, S., and Lynch, G. (1989). Long-lasting physiological effects of bath applied N-methyl-D-aspartate. Brain Res. 476, 170-173. doi: 10.1016/0006-8993(89)91553-9

Tonegawa, S., Morrissey, M. D., and Kitamura, T. (2018). The role of engram cells in the systems consolidation of memory. Nat. Rev. Neurosci. 19, 485-498. doi: 10.1038/s41583-018-0031-2

Tsokas, P., Hsieh, C., Yao, Y., Lesburgueres, E., Wallace, E. J., Tcherepanov, A., et al. (2016). Compensation for PKMzeta in long-term potentiation and spatial long-term memory in mutant mice. eLife 5:e14846. doi: 10.7554/eLife. 14846

Tyssowski, K. M., DeStefino, N. R., Cho, J.-H., Dunn, C. J., Poston, R. G., Carty, C. E., et al. (2018). Different neuronal activity patterns induce different gene expression programs. Neuron 98, 530.e11-546.e11. doi: 10.1016/j.neuron.2018. 04.001

Vecsey, C. G., Hawk, J. D., Lattal, K. M., Stein, J. M., Fabian, S. A., Attner, M. A., et al. (2007). Histone deacetylase inhibitors enhance memory and synaptic plasticity via CREB: CBP-dependent transcriptional activation. J. Neurosci. 27, 6128-6140. doi: 10.1523/JNEUROSCI.0296-07.2007

Vician, L., Lim, I. K., Ferguson, G., Tocco, G., Baudry, M., and Herschman, H. R. (1995). Synaptotagmin IV is an immediate early gene induced by depolarization in PC12 cells and in brain. Proc. Natl. Acad. Sci. U.S.A. 92, 2164-2168. doi: 10.1073/pnas.92.6.2164

Wang, Z., Zang, C., Cui, K., Schones, D. E., Barski, A., Peng, W., et al. (2009). Genome-wide mapping of HATs and HDACs reveals distinct functions in active and inactive genes. Cell 138, 1019-1031. doi: 10.1016/j.cell.2009. 06.049 
Webb, W. M., Sanchez, R. G., Perez, G., Butler, A. A., Hauser, R. M., Rich, M. C., et al. (2017). Dynamic association of epigenetic H3K4me3 and DNA $5 \mathrm{hmC}$ marks in the dorsal hippocampus and anterior cingulate cortex following reactivation of a fear memory. Neurobiol. Learn. Mem. 142, 66-78. doi: 10.1016/ j.nlm.2017.02.010

Wee, C. L., Teo, S., Oey, N. E., Wright, G. D., VanDongen, H. M., and VanDongen, A. M. (2014). Nuclear arc interacts with the histone acetyltransferase Tip60 to modify H4K12 Acetylation(1,2,3). eNeuro 1:ENEURO.0019-14.2014. doi: 10.1523/ENEURO.0019-14.2014

Whitlock, J. R., Heynen, A. J., Shuler, M. G., and Bear, M. F. (2006). Learning induces long-term potentiation in the hippocampus. Science 313, 1093-1097. doi: $10.1126 /$ science. 1128134

Williams, J. M., Beckmann, A. M., Mason-Parker, S. E., Abraham, W. C., Wilce, P. A., and Tate, W. P. (2000). Sequential increase in Egr-1 and AP-1 DNA binding activity in the dentate gyrus following the induction of longterm potentiation. Mol. Brain Res. 77, 258-266. doi: 10.1016/S0169-328X(00) 00061-9

Wisden, W., Errington, M. L., Williams, S., Dunnett, S. B., Waters, C., Hitchcock, D., et al. (1990). Differential expression of immediate early genes in the hippocampus and spinal cord. Neuron 4, 603-614. doi: 10.1016/08966273(90)90118-Y

Wood, M. A., Kaplan, M. P., Park, A., Blanchard, E. J., Oliveira, A. M. M., Lombardi, T. L., et al. (2005). Transgenic mice expressing a truncated form of CREB-binding protein (CBP) exhibit deficits in hippocampal synaptic plasticity and memory storage. Learn. Mem. 12, 111-119. doi: 10.1101/lm. 86605
Yamagata, K., Andreasson, K. I., Sugiura, H., Maru, E., Dominique, M., Irie, Y., et al. (1999). Arcadlin is a neural activity-regulated cadherin involved in long term potentiation. J. Biol. Chem. 274, 19473-11979. doi: 10.1074/jbc.274.27.19473

Yilmaz-Rastoder, E., Miyamae, T., Braun, A. E., and Thiels, E. (2011). LTP- and LTD-inducing stimulations cause opposite changes in arc/arg3.1 mRNA level in hippocampal area CA1 in vivo. Hippocampus 21, 1290-1301. doi: 10.1002/ hipo. 20838

Zhang, W., and Linden, D. J. (2003). The other side of the engram: experiencedriven changes in neuronal intrinsic excitability. Nat. Rev. Neurosci. 4, 885-900. doi: $10.1038 / \mathrm{nrn} 1248$

Zhou, Y., Won, J., Karlsson, M. G., Zhou, M., Rogerson, T., Balaji, J., et al. (2009). CREB regulates excitability and the allocation of memory to subsets of neurons in the amygdala. Nat. Neurosci. 12, 1438-1443. doi: 10.1038/nn. 2405

Conflict of Interest Statement: The authors declare that the research was conducted in the absence of any commercial or financial relationships that could be construed as a potential conflict of interest.

Copyright (c) 2018 Kyrke-Smith and Williams. This is an open-access article distributed under the terms of the Creative Commons Attribution License (CC BY). The use, distribution or reproduction in other forums is permitted, provided the original author(s) and the copyright owner(s) are credited and that the original publication in this journal is cited, in accordance with accepted academic practice. No use, distribution or reproduction is permitted which does not comply with these terms. 